\title{
Sensitivities of Lagrangian modelling of mid-latitude cirrus clouds to trajectory data quality
}

\author{
E. Kienast-Sjögren ${ }^{1, \mathrm{a}}$, A. K. Miltenberger ${ }^{1, \mathrm{~b}}$, B. P. Luo ${ }^{1}$, and T. Peter ${ }^{1}$ \\ ${ }^{1}$ Institute for Atmospheric and Climate Science, ETH Zurich, Switzerland \\ ${ }^{a}$ now at: Federal Office of Meteorology and Climatology MeteoSwiss, Federal Department of Home Affairs, \\ Zurich Airport, Switzerland \\ ${ }^{\mathrm{b}}$ now at: Institute for Climate and Atmospheric Science, University of Leeds, Leeds, UK \\ Correspondence to: E. Kienast-Sjögren (erika.kienast@meteoswiss.ch)
}

Received: 20 February 2015 - Published in Atmos. Chem. Phys. Discuss.: 11 March 2015

Revised: 18 June 2015 - Accepted: 22 June 2015 - Published: 09 July 2015

\begin{abstract}
Simulations of cirrus are subject to uncertainties in model physics and meteorological input data. Here we model cirrus clouds along air mass trajectories, whose extinction has been measured with an elastic backscatter lidar at Jungfraujoch research station in the Swiss Alps, with a microphysical stacked box model. The sensitivities of these simulations to input data uncertainties (trajectory resolution, unresolved vertical velocities, ice nuclei number density and upstream specific humidity) are investigated.

Variations in the temporal resolution of the wind field data (COSMO-Model at $2.2 \mathrm{~km}$ resolution) between $20 \mathrm{~s}$ and $1 \mathrm{~h}$ have only a marginal impact on the trajectory path, while the representation of the vertical velocity variability and therefore the cooling rate distribution are significantly affected. A temporal resolution better than $5 \mathrm{~min}$ must be chosen in order to resolve cooling rates required to explain the measured extinction. A further increase in the temporal resolution improves the simulation results slightly. The close match between the modelled and observed extinction profile for high-resolution trajectories suggests that the cooling rate spectra calculated by the COSMO-2 model suffice on the selected day. The modelled cooling rate spectra are, however, characterized by significantly lower vertical velocity amplitudes than those found previously in some aircraft campaigns (SUCCESS, MACPEX). A climatological analysis of the vertical velocity amplitude in the Alpine region based on COSMO-2 analyses and balloon sounding data suggests large day-to-day variability in small-scale temperature fluctuations. This demonstrates the necessity to apply numerical weather prediction models with high spatial and tempo-
\end{abstract}

ral resolutions in cirrus modelling, whereas using climatological means for the amplitude of the unresolved air motions does generally not suffice.

The box model simulations further suggest that uncertainties in the upstream specific humidity $( \pm 10 \%$ of the model prediction) and in the ice nuclei number density $\left(0-100 \mathrm{~L}^{-1}\right)$ are more important for the modelled cirrus cloud than the unresolved temperature fluctuations if temporally highly resolved trajectories are used. For the presented case the simulations are incompatible with ice nuclei number densities larger than $20 \mathrm{~L}^{-1}$ and insensitive to variations below this value.

\section{Introduction}

Cirrus clouds are an important component of the climate system because they influence the radiative budget by scattering solar radiation back to space and by trapping longwave radiation in the troposphere. The balance between these two mechanisms determines the overall radiative effect of cirrus clouds on the climate. In general it is assumed that cirrus clouds have a warming effect on climate (e.g. Chen et al., 2000), but the magnitude of this effect depends strongly on the optical thickness and cloud top temperature (e.g. Stephens et al., 1990; Corti and Peter, 2009). The optical thickness of cirrus depends on the nucleation properties of the pre-existing aerosols and on the local cooling rates, which both determine the ice crystal number density and crystal size. The optical thickness further depends on 
the atmospheric relative humidity profile, limiting the geometric thickness of the cloud. Finally, the cloud top temperature determines the cloud emissivity (Platt and Harshvardhan, 1988; Ebert and Curry, 1992; Lin et al., 1998a; Chen et al., 2000). In addition, the shape and orientation of the ice crystals influence the radiative properties of cirrus clouds, but both variables are not known in general and hard to determine from measurements (e.g. Stephens et al., 1990). While mid-latitude cirrus have been studied by several authors (e.g. Chen et al., 2000; Fusina et al., 2007; Cziczo and Froyd, 2014), the magnitude of the positive cloud radiative forcing remains uncertain. The microphysical processes leading to cirrus formation are not yet completely understood. Further, the coarse parameterization of cirrus clouds contributes to the uncertainties of radiative forcing predicted by climate models (Dessler and Yang, 2003; Solomon et al., 2007; Myhre et al., 2013). We note here that the overall radiative forcing effect by cirrus clouds is smaller than the effect of liquid and mixed-phase clouds situated further down in the troposphere (Chen et al., 2000; Sherwood et al., 2014; Kienast-Sjögren et al., 2015). Thus, the uncertainties in the radiative forcing of clouds in climate models can to a large part be attributed to uncertainties considering low clouds and convective mixing (Sherwood et al., 2014).

To better understand mid-latitude cirrus clouds and their effect on climate, we need to improve our knowledge on their formation mechanisms and to better constrain the uncertainties involved in cloud modelling. For this purpose, the formation of cirrus clouds has been investigated with detailed microphysical box models applied in the case studies (or with column models, i.e. stacked box models, which allow sedimentation to be taken into account). The box model simulations are usually conducted along backward trajectories, which provide the required temperature and pressure history of the air parcels (e.g. Jensen et al., 1994a, b; Haag and Kärcher, 2004; Hoyle et al., 2005; Comstock et al., 2008; Brabec et al., 2012; Rolf et al., 2012; Jensen et al., 2013; Cirisan et al., 2014). The Zurich Optical and Microphysical Model (ZOMM; Luo et al., 2003a, b), the Model for Aerosol and Ice Dynamics (MAID; Bunz et al., 2008) and the Advanced Particle Simulation Code (APSC; Kärcher, 2003) are some of the models used. Studies using these models entail a number of uncertainties in the following quantities:

a. the trajectory path as well as the traced thermodynamic fields $T$ and $p$ resulting either from uncertainties in the dynamic fields $v$ or the trajectory calculation method;

b. the representation of small-scale vertical motions leading to small-scale temperature fluctuations $(\mathrm{d} T / \mathrm{d} t)_{\mathrm{ss}}$, which are not resolved by the underlying numerical model;

c. the initial specific humidity $q_{v}(t=0)$;

d. simulations with homogeneous nucleation only and simulations with homogeneous as well as heteroge- neous nucleation with varying initial ice nuclei number densities $n_{\mathrm{IN}}(t=0)$.

These uncertainties and their implications for cirrus cloud modelling are investigated in this study.

Uncertainty (a) concerns the motion of the cloud-forming parcels and their thermodynamic history. The calculation of the paths of these air parcels relies on the advection of point masses with the wind field predicted by a numerical weather prediction (NWP) model. Accordingly, their accuracy depends on the accuracy of the modelled wind fields as well as the trajectory calculation method used. While current stateof-the-art high-resolution NWP models have a sufficient resolution to resolve mesoscale motions for instance over mountainous areas, the predicted wind field may suffer from errors in the initial and boundary conditions and deficiencies in the model physics, particularly regarding parameterized processes. Uncertainties due to the trajectory calculation method are mainly linked to the applied integration method and the spatial and temporal interpolation of the wind field to the actual parcel location (e.g. Stohl, 1998). Previous studies have shown that excessive temporal interpolation can strongly affect the resulting trajectories (e.g. Stohl et al., 1995, 2001). However, the impact of these uncertainties on cirrus cloud modelling has received little attention so far.

Uncertainty (b) relates to the cooling rate in the very moment of the nucleation event, which influences the number of nucleated ice crystals and thus determines the cirrus morphology (Lin et al., 1998b; Kärcher and Ström, 2003; Haag and Kärcher, 2004; Koop, 2004; Hoyle et al., 2005). While temperature variations at spatial scales of several tens of kilometres can be captured by regional NWP models, vertical velocity and temperature fluctuations at smaller spatial scales remain unresolved due to limited spatial resolution. Several studies have resorted to including the unresolved vertical motions in cirrus cloud modelling by superimposing artificial fluctuations on the trajectory data (Hoyle et al., 2005; Brabec et al., 2012; Rolf et al., 2012; Spichtinger and Krämer, 2013; Cirisan et al., 2014; Murphy, 2014; Dinh et al., 2015). Amplitudes and frequency distributions of the unresolved motions are typically taken from field measurements, which are unrelated to the investigation at hand. For this, most previous studies utilized measured power spectral densities (PSDs) of temperature, e.g from the SUCCESS campaign (Hoyle et al., 2005) or the INCA campaign (e.g, Haag and Kärcher, 2004). Whether these PSDs are applicable to geographic locations and meteorological conditions other than during the measurement campaigns remains unclear. As an alternative, NWP model data become available at successively higher spatial resolution, but here it remains unclear which fraction of the vertical velocity variability is actually explicitly resolved by the NWP model and in the derived trajectory data.

Uncertainty (c) limits the accuracy of the relative humidity of an air parcel. The humidity is usually retrieved from stateof-the-art NWP models, although with large uncertainties in 
the upper troposphere (Kunz et al., 2014). As ice nucleation occurs at a certain ice supersaturation, humidity errors can lead to significant shifts in the onset of ice nucleation as well as in the number of nucleated ice crystals (Dinh et al., 2015).

Finally, uncertainty (d), i.e. the lack of knowledge on ice nuclei number density $n_{\mathrm{IN}}$ in the investigated air parcel, affects the results of cirrus cloud modelling. Ice nuclei, whose number densities are typically between 10 and $100 \mathrm{~L}^{-1}$ (per standard litre) (DeMott et al., 2010), lead to heterogeneous nucleation on solid particles such as dust and ash (Pruppacher and Klett, 1997; Kärcher and Lohmann, 2003; Wiacek et al., 2010; Cziczo et al., 2013; Cziczo and Froyd, 2014). Heterogeneous nucleation results in cirrus with lower number densities than homogeneous nucleation in metastable solution droplets (Lin et al., 1998a; Koop et al., 2000; Kärcher and Ström, 2003). In addition, the nucleation mode determines the ice supersaturation at which the nucleation starts (Koop et al., 2000; Koop, 2004), and thus the location of nucleation onset. Knowledge of $n_{\mathrm{IN}}$ is available only under the special conditions of concomitant aircraft-borne ice nuclei measurements.

In general, the uncertainties discussed above also pertain to the modelling of cirrus clouds with Eulerian models, except for the uncertainty in the trajectory path (a). Several studies have addressed these uncertainties in individual case studies in Lagrangian and Eulerian modelling frameworks (e.g. Jensen et al., 1994b, 2013; Hoyle et al., 2005; Cirisan et al., 2014; Muhlbauer et al., 2014a, b). Most studies have focused on the role of different representations of ice nucleation and small-scale temperature fluctuations, while the impact of the temporal resolution of the trajectory data (not relevant for Eulerian studies) and forecast errors in the initial moisture content has so far received less attention. In this study we investigate the representation of small-scale temperature and vertical velocity fluctuations in the COSMO-2 model and along trajectories computed with wind fields at different temporal resolutions between $20 \mathrm{~s}$ and $1 \mathrm{~h}$ for a lidar measurement case study above Jungfraujoch in the Swiss Alps. We further analyse the impact of variations in the initial humidity and ice nuclei number density within their respective uncertainty range on the modelling results for the same case study.

\section{Methods and data}

\subsection{Lidar measurement}

The cirrus cloud measurements used in this study were conducted with an elastic backscatter lidar (light detection and ranging; Leosphere ALS-450). This commercial Lidar emits laser pulses with a wavelength of $355 \mathrm{~nm}$, a repetition rate of $20 \mathrm{~Hz}$, and an average pulse energy of $16 \mathrm{~mJ}$. It detects attenuated backscatter, both in parallel and perpendicular polarization, enabling a determination of the sphericity and thus the physical state of the scattering particles (Schotland et al., 1971; Kovalev and Eichinger, 2004; Zieger et al., 2012).

The lidar was situated at the high-alpine research station Jungfraujoch at $3580 \mathrm{~m}$ above sea level (a.s.1.) in the Swiss Alps. Jungfraujoch enables lidar measurements of the highest quality due to its unique location above the polluted boundary layer. The high altitude also shortens the distance between the lidar and the scatterer, which further improves the quality of the range-corrected attenuated backscatter signal.

The retrieved signal can be described using the following lidar equation (Ansmann et al., 1992; Kovalev and Eichinger, 2004):

$$
r^{2} P(r)=C\left[\beta_{\mathrm{m}}(r)+\beta_{\mathrm{p}}(r)\right] \exp \left(-2 \int_{0}^{r}\left[\alpha_{\mathrm{m}}\left(r^{\prime}\right)+\alpha_{\mathrm{p}}\left(r^{\prime}\right)\right] \mathrm{d} r^{\prime}\right),
$$

where $r^{2} P(r)$ describes the range-corrected signal detected by the lidar, $\beta_{\mathrm{m}}$ and $\beta_{\mathrm{p}}$ denote the backscatter coefficient by the molecules and particles, respectively, and $\alpha_{\mathrm{m}}$ and $\alpha_{\mathrm{p}}$ specify molecular and particulate extinction coefficient at the range $r$ above the lidar. The constant $C$ describes instrumental properties such as the calibration and overlap functions. The molecular backscatter and extinction coefficients are calculated using COSMO-2 analysis data of pressure and temperature. We will compare the model results with the lidar measurements in terms of the cloud extinction coefficient, because the simulated extinction coefficient can be calculated directly from the surface area density of the simulated particles from the microphysical box model ZOMM. The extinction coefficient is related to the backscatter coefficient via the "lidar ratio" (i.e. the ratio between optical extinction and $180^{\circ}$ backscatter at the laser wavelength). We use a lidar ratio of $20 \mathrm{sr}^{-1}$. This value was determined as the most suitable using a lidar inversion with both a far-end and nearend boundary condition (Klett, 1981). Using the lidar inversion described in Kovalev and Eichinger (2004), the particulate backscatter ratio and extinction coefficient are determined. The profiles are corrected for multiple scattering using the model of Hogan (2008) by the method described in Wandinger (1998) or Seifert et al. (2007).

In the evaluation of the lidar data we have taken into account uncertainties in the lidar signal itself (due to statistical uncertainty in the counting of photons), uncertainties in the assumption of lidar ratio, and uncertainties in the molecular properties retrieved from COSMO-2 analysis data. The measurement uncertainties pertain only to the absolute extinction value. However, the vertical position of the cloud, which is most important for the comparison with the model results, is not subject to measurement uncertainties (e.g. Fig. 8 below).

Figure 1 shows the lidar measurements of 22 November 2011 used in the current study. On this day an almost persistent cirrus cloud cover is observed over Jungfraujoch from 04:00 UTC onwards. The cirrus cloud had a vertical extent of about $1.5 \mathrm{~km}$ with the cloud top located at approxi- 
mately $11.5 \mathrm{~km}$ a.s.l. For the investigation in this paper we focus on 09:00 UTC. For the comparison to the modelling results we use the mean extinction profile in a 20 min interval around 09:00 UTC. While the observations show an almost constant height of the cloud top and bottom during this time period, the measured extinction varies somewhat during this time interval. This, however, does not influence our conclusions as for the modelled extinction profiles variations in the extinction are almost always coupled to changes in cloud height. The optical depth of the cirrus cloud during the considered time interval was 0.06 , which is classified according to Sassen and Comstock (2001) as a thin cirrus, on the limit to subvisible $(\tau<0.03)$.

\subsection{Numerical model data}

\subsubsection{Eulerian model setup}

The non-hydrostatic, regional numerical weather prediction model COSMO (Baldauf et al., 2011) was used to predict the motion of the air masses, in which the observed cirrus cloud forms. The simulations were performed for the time period between 12:00 UTC on 20 November 2011 and 12:00 UTC on 22 November 2011 at a spatial resolution of $2.2 \mathrm{~km}$. The domain of the simulation covers the area between approximately 42.7 and $49.6^{\circ} \mathrm{N}$ and 0 and $17^{\circ} \mathrm{E}$. In the vertical we use a Gal-Chen hybrid coordinate system with $60 \mathrm{lev}$ els, which provides an average vertical resolution of $388 \mathrm{~m}$. The spacing of levels gradually increases from $13 \mathrm{~m}$ close to the model surface to $1190 \mathrm{~m}$ at the model top $(23 \mathrm{~km})$. For the initial and boundary conditions we used the operational analysis of the Swiss weather service at $6.6 \mathrm{~km}$ horizontal resolution. The topography was filtered with a fourth-order lowpass filter based on Raymond (1988), resulting in a cut-off of orographic features at approximately $4 \Delta x$. In addition the impact of sub-grid-scale orography on the drag and gravity wave generation is parameterized based on Lott and Miller (1997). In the simulation turbulence, soil processes, radiation and shallow convection (Tiedtke scheme) are all parameterized. Deep convection is not parameterized as it is explicitly resolved. Microphysical processes are parameterized by the standard single-moment scheme with five hydrometeor classes operationally used in the model (Reinhardt, 2006) (which is replaced by the comprehensive ZOMM microphysics in the subsequent trajectory calculations, Sect. 2.3). The time step for the model simulation is $20 \mathrm{~s}$. The model output is available either as Eulerian fields at a temporal resolution of $5 \mathrm{~min}$ or directly along online calculated trajectories at a temporal resolution of $20 \mathrm{~s}$ (Sect. 2.2.2).

In order to obtain the best possible representation of the real atmospheric conditions, observational data routinely used for the COSMO analysis by MeteoSwiss was used for nudging of the simulation (based on the method of Schraff, 1996, 1997). The COSMO-2 model simulation predicts an ice-phase cloud above Jungfraujoch in the same time and alti-

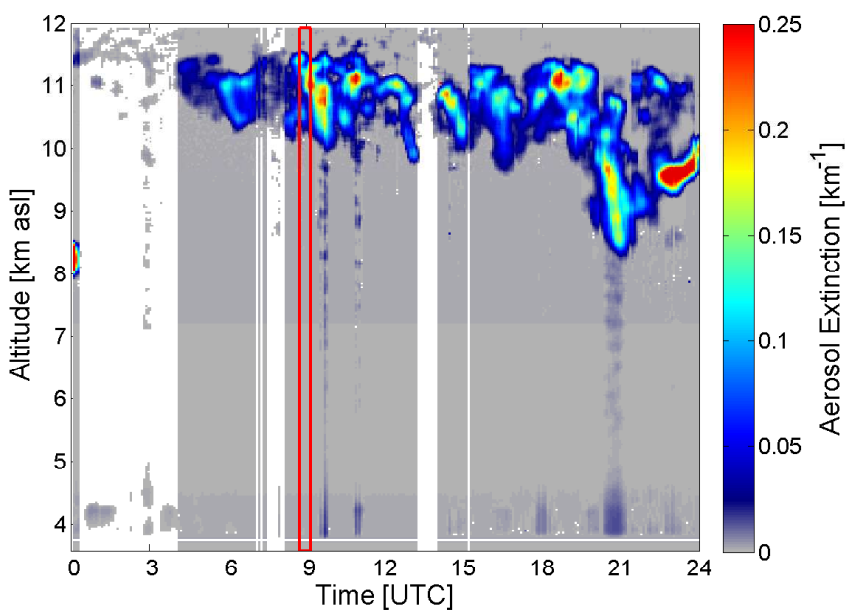

Figure 1. Lidar measurement at Jungfraujoch on 22 November 2011. Colours: aerosol extinctions retrieved from measured backscatter.

tude range at which it was observed by the lidar (not shown). While this indicates a suitable representation of the thermodynamic conditions in the model, the rather coarse vertical resolution of the model in the upper troposphere with only three levels between 10.5 and $11.0 \mathrm{~km}$ may hamper the representation of processes with small vertical scales. The vertical resolution is increased to $100 \mathrm{~m}$ by vertical interpolation (see Sect. 2.2.2) for the ZOMM simulations. This allows a better representation of cloud microphysical processes. The upstream moisture profile, gravity wave amplitudes and phases are presumable not adversely affected by the interpolation, because these fields are rather smooth over the considered height interval.

\subsubsection{Trajectory data}

The wind fields from the COSMO-2 model simulation described above were used offline to calculate air mass trajectories at temporal resolutions between $1 \mathrm{~min}$ and $1 \mathrm{~h}$ with LAGRANTO (Wernli and Davies, 1997). These trajectories are referred to in the following as "offline trajectories". In addition, a new module of the COSMO-2 model was used which allows for trajectories to be calculated during the model integration (Miltenberger et al., 2013). This novel method makes use of the wind fields at every Eulerian model time step (here: $20 \mathrm{~s}$ ) and therefore provides very accurate and temporally highly resolved trajectories. These are referred to as "online trajectories".

\section{Offline trajectories}

These have been calculated in the standard manner as backward trajectories, based on the conventional COSMO-Model output fields. The backward trajectories start above Jungfraujoch between 8 and $12 \mathrm{~km}$ altitude with a spacing of $100 \mathrm{~m}$ 
at 09:00 UTC on 22 November 2011. The wind fields were taken from the COSMO-2 model output of the nudged simulation either at hourly or at $5 \mathrm{~min}$ temporal resolution. When hourly wind fields were used (i.e. ignoring 11 of the 12 output fields at $5 \mathrm{~min}$ resolution), the trajectory integration time step was chosen as $5 \mathrm{~min}$, and the trajectory output was made available every $5 \mathrm{~min}$. For the $5 \mathrm{~min}$ COSMO-2 model output fields (nudged forecast), the trajectory integration time step was $1 \mathrm{~min}$. Trajectory output is used at 5 and $1 \mathrm{~min}$ intervals.

\section{Online trajectories}

Online trajectories can only be computed forward in time. In the COSMO-Model simulation, trajectories were started every $15 \mathrm{~min}$ between 21:00 UTC on 21 November and 00:00 UTC on 22 November 2011 along the western domain boundary at a horizontal spacing of $0.02^{\circ}$ and with a vertical spacing of $25 \mathrm{~m}$ at altitudes between 8 and $12 \mathrm{~km}$. This gives a total of 1964200 trajectories. This large number is required to get enough trajectories over Jungfraujoch at the right time and at a reasonable vertical spacing. For the analysis we consider only air parcels travelling through a column of $0.01^{\circ} \times 0.01^{\circ}$ geographic extent centred at Jungfraujoch (i.e. roughly $1 \mathrm{~km} \times 1 \mathrm{~km}$ ), which results in 9793 trajectories (about $0.5 \%$ of all trajectories). This includes a subset of 354 trajectories which pass over Jungfraujoch between 08:50 and 09:10 UTC, the period chosen for closer comparison with the lidar measurements. Above Jungfraujoch, these selected online trajectories have a vertical spacing varying between 86 and $124 \mathrm{~m}$. with a mean of $100 \mathrm{~m}$. Temperature, pressure, specific humidity, vertical velocity and ice water content are traced along the trajectories.

\subsection{Microphysical box model ZOMM}

In order to investigate the microphysical evolution of the cirrus cloud observed above Jungfraujoch, we use the microphysical box model ZOMM (Zurich Optical and Microphysical Model), which was previously developed to investigate polar stratospheric clouds (e.g. Luo et al., 2003b; Engel et al., 2013) and cirrus clouds (e.g. Luo et al., 2003a; Hoyle et al., 2005; Brabec et al., 2012; Cirisan et al., 2014). ZOMM is forced with thermodynamic data $(T, p)$ from the trajectories and is initialized with the COSMO-2 model humidity at the trajectory starting point. ZOMM takes uptake and release of water vapour by ice crystals as well as solution droplets into account. For further details on ZOMM we refer the reader to Sect. 3.4 in Cirisan et al. (2014). We treat ice nucleation as pure homogeneous nucleation of metastable solution droplets based on Koop et al. (2000) or, alternatively, with additional heterogeneous nucleation on solid particles such as dust or ash as suggested by Marcolli et al. (2007) for Arizona Test Dust. For simulations including heterogeneous nucleation we used ice nuclei concentrations of 10, 20, 50 and $100 \mathrm{~L}^{-1}$ (per volume of ambient air). These concen- trations cover the range of free-tropospheric background ice nuclei number densities at mid-latitudes, typically ranging between 10 and $30 \mathrm{~L}^{-1}$ (Haag and Kärcher, 2004; DeMott et al., 2010).

We ran the box model along offline backward trajectories and online trajectories derived from the nudged COSMOModel simulation. The microphysical box model is run forward in time for all trajectory data sets. Sedimentational fluxes from higher to lower level parcels are taken into account by ZOMM. The total water in the level is increasing due to sedimentation from the level above and decreasing due to sedimentation to the lower level. The ice particles falling from the level above will grow and decrease the supersaturation if the air mass is supersaturated, and vice versa. ZOMM uses a log-normal size distribution. It is initialized with 100 logarithmically spaced size bins. The number and radius of each size bin is allowed to change during the model run. We assume $250 \mathrm{~cm}^{-3}$ sulfate particles. Their sizes are distributed log-normally with a mode radius of $0.05 \mu \mathrm{m}$ and a sigma of 1.4. In the model, we apply a dynamic time step. The composition of liquid solution will change by a maximum of $0.1 \%$ in the nucleation regions and $1 \%$ for other regions during one time step. By its nature, the model does not account for vertical or horizontal shear of the trajectories. This is an approximation that ZOMM shares with all column models. This might be acceptable given that the cloud observed by lidar on 22 November 2011 above Jungfraujoch extended over many hours and has a comparable small geometrical thickness, though there is significant wind shear in the upper troposphere during the considered case study (Sect. 3.1).

\subsection{Evaluation method for simulations}

We compare the cirrus clouds modelled along different trajectory data sets to the cirrus cloud observed by lidar above Jungfraujoch. For this comparison we calculate the extinction from the surface area density in the ZOMM model output. We chose to analyse the extinction (instead of the backscatter) as it can be directly calculated from the surface area of the nucleated particles. The backscatter ratio requires an assumption about the aspect ratio of the ice particles to use the T-matrix method to solve the Maxwell equations describing $180^{\circ}$ scattering of light by non-perfectly spherical particles (Mishchenko et al., 2010). Extinction, in turn, is much less sensitive to shape effects.

\section{SAL metric}

To compare the simulated and the measured extinction profiles, an objective evaluation measure is needed: one option is to use bulk error measures such as the root-mean-squared error or the logarithmic error measure introduced by Cirisan et al. (2014). These measures allow a point-by-point comparison between the profiles, but they do not allow a more thorough analysis of the reason for any forecasting defi- 
ciency. Therefore we use the SAL error measure introduced by Wernli et al. (2008) and adopt it to our 1-D profiles. The SAL consists of three different components: the first term, structure $S$, compares the shape of the formed cloud, e.g. whether there is a very narrow cloud or a cloud with a large vertical extent. $S$ can take values between -2 and 2 . The cloud is predicted to have a larger (smaller) vertical extent than in the observations if $S$ is positive (negative). The second term, amplitude $A$, quantifies the error in terms of underor overestimating the measured cloud extinction, regardless of the vertical position of the cloud. $A$ can take values between -2 and $2 ; A=1(A=-1)$ when the modelled average extinction is larger (smaller) by a factor of 3 than the observed extinction. Finally, the location $L$ describes the error in the vertical position of the centre of mass of the cloud. $L$ can take values between 0 and 2 , where $L=2$ means that the cloud occurs at the top of the vertical profile in one data set and at the bottom in the other. In a perfect forecast, all three components $(S, A, L)$ are equal to zero.

\section{Trajectories and cooling rates}

\subsection{Air mass origin and path}

The origin of the air masses, in which the measured cirrus cloud forms, is crucial for process understanding and modelling, because it controls the amount of water vapour available for condensation and the potential degree of ice supersaturation. In particular, the path of the air parcel determines the location and time of the first nucleation event via controlling the supersaturation and the number of nucleating ice crystals via controlling the cooling rate during nucleation. The path of the air parcels which arrived above Jungfraujoch at the time the cirrus cloud was observed is shown in Fig. 2 . The trajectories shown in the left panel are based on wind fields at a temporal resolution of $5 \mathrm{~min}$, while the right panel shows online trajectories, i.e. based on $20 \mathrm{~s}$ wind field data. The colour bar indicates the altitudes at which the trajectories arrived at Jungfraujoch on 09:00 UTC on 22 November 2011.

In general parcels arriving at altitudes between 8 and $12 \mathrm{~km}$ above Jungfraujoch are located just north of the Massif Central $10 \mathrm{~h}$ earlier and approach the Alps from a northwesterly direction. A significant spread of the trajectories in the horizontal is observed. In addition, there are significant differences in travel speeds between online and offline trajectories. The spread and the different travel speed on the air parcels can be problematic for column microphysical models, because these models do not take horizontal or vertical shear into account. This may lead to significant errors as sedimenting ice crystals may enter lower trajectories at unrealistic times. If only trajectories relevant for the observed cirrus cloud are considered, i.e. those arriving between 10.5 and $11.5 \mathrm{~km}$ a.s.l., the spread is somewhat reduced (yellow to or-

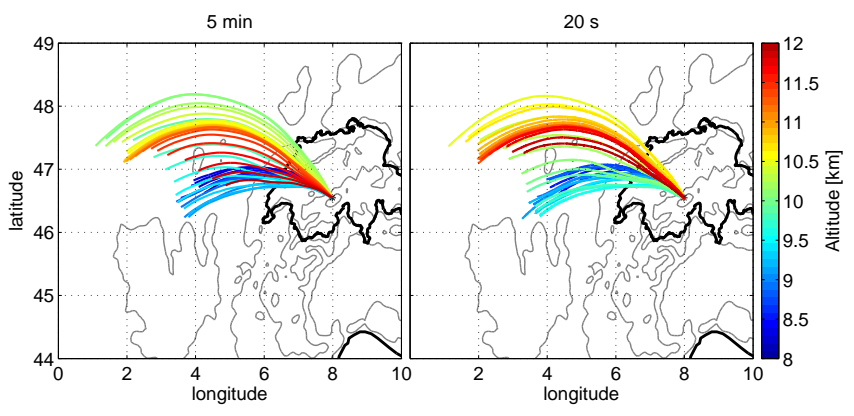

Figure 2. Offline (left) and online (right) trajectories arriving above Jungfraujoch at 09:00 UTC on 22 November 2011. Offline trajectories: based on $5 \mathrm{~min}$ wind field data. Trajectory lengths: plotted for $10 \mathrm{~h}$ or until they leave the domain. Colour coding: trajectory altitude upon their arrival above Jungfraujoch. Thick contours: Swiss border as well as coast of the Mediterranean Sea. Grey contour lines: topography from the COSMO-2 model.

ange colours in Fig. 2). More importantly, the simulation results show that the air parcels most crucial for the formation of the observed cirrus cloud are not affected by ice crystals falling out of higher-level parcels (Fig. 6 later). Accordingly, these parcels can be considered as decoupled from the trajectory stack and therefore as unaffected by any assumptions on horizontal and temporal alignment for the sedimentation treatment. The evaporation of the ice crystals in lower parcels may, however, be affected by the treatment of sedimentation, as crystals from earlier nucleation events modify the specific moisture content in these parcels (Fig. 6 later).

The horizontal travel path of online and offline trajectories is rather similar. In the $10 \mathrm{~h}$ prior to arrival at Jungfraujoch, paths deviate by less than $100 \mathrm{~km}$. In the vertical the paths of online and offline trajectories are also very similar, with a maximum vertical deviation of about $500 \mathrm{~m}$. Despite the overall similarity of the trajectory paths, some distinct differences particularly in the vertical path can be observed: for instance, the most northerly trajectory from the online and offline data set show a very similar geographical path but reach Jungfraujoch at different altitudes, $500 \mathrm{~m}$ apart. Ten hours before reaching Jungfraujoch, the two trajectories are almost at the same location. Their horizontal winds are very similar, but their vertical winds differ significantly. The online trajectories ascent strongly by $300 \mathrm{~m}$ about $2 \mathrm{~h}$ before reaching Jungfraujoch. The offline trajectories, on the other hand, display a slight descent in the same time period (not shown). These differences have a considerable impact on the cirrus formation, as they display very different cooling rates (see below).

According to the rather similar horizontal and vertical location of the source region, the specific water vapour concentration $10 \mathrm{~h}$ before arrival at Jungfraujoch is almost identical in the different trajectory data sets (not shown). The initial moisture content of trajectories arriving at around $9 \mathrm{~km}$ a.s.l. 
is about $80 \mathrm{mg} \mathrm{kg}^{-1}$ and decreases almost linearly with elevation to about $10 \mathrm{mg} \mathrm{kg}^{-1}$ at $12 \mathrm{~km}$ a.s.l.

\subsection{Temperature fluctuations}

Small-scale temperature fluctuations have been shown to be very important for cirrus cloud formation (e.g. Hoyle et al., 2005; Brabec et al., 2012; Rolf et al., 2012; Engel et al., 2013; Cirisan et al., 2014), because the cooling rate in the very moment of the nucleation event affects the nucleation rate (in particular for homogeneous nucleation). These temperature fluctuations remain largely unresolved in state-of-the-art NWP models due to their limited spatial resolution.

With $\Delta x=2.2 \mathrm{~km}$ horizontal grid spacing, only waves with wavelengths larger than $4 \Delta x=8.8 \mathrm{~km}$ can be resolved. Recent studies have shown that the effective model resolution is typically even somewhat lower, depending on the treatment of turbulence and numerical diffusion: Bierdel et al. (2012) find an effective model resolution of about $4-5 \Delta x$ for the COSMO-2 model domain over Germany (COSMODE), while Skamarock (2004) finds an effective resolution of about $7 \Delta x$ for WRF simulations during the BAMEX campaign. Here we continue to assume a resolution of $4 \Delta x$, which for stationary waves and air parcels travelling with velocities between 10 and $50 \mathrm{~m} \mathrm{~s}^{-1}$ (typical for the middle and upper troposphere) corresponds to wave periods between 2.9 and $14.7 \mathrm{~min}$. In order to correctly represent all waves resolved by the Eulerian model in the trajectory data, at least four points are required during the wave period. This requires a temporal resolution of $44 \mathrm{~s}$ to $3.7 \mathrm{~min}$ depending on the travel speed.

In stark contrast, most trajectory calculation tools rely on NWP model output at a temporal resolution between 1 and $6 \mathrm{~h}$. Calculating trajectory data at the required temporal resolution calls for massive temporal interpolation of the wind fields. Such interpolation (e.g. from 1-hourly Eulerian output fields to $5 \mathrm{~min}$ trajectory steps) has been used extensively in past investigations, and it has been shown that the interpolated data provide cooling and heating rates which are in much better agreement with 5 min based data sets than trajectory data providing only the hourly trajectory data (see Appendix C of Brabec et al., 2012). This suggests that interpolating trajectory data is actually a microphysically sensible procedure, because the interpolated trajectory points pick up the high spatial resolution of the underlying Eulerian grid, including orography and weather systems, even when the temporal storage is only hourly. Horizontal winds chase the air parcels faster across this texture than the texture changes itself as function of time (Brabec et al., 2012). Nevertheless the required temporal interpolation can introduce significant errors in wave amplitude and phase, in particular when trajectories pass through non-stationary waves. A new trajectory calculation tool is available which mitigates the problems introduced by temporal interpolation of wind field data

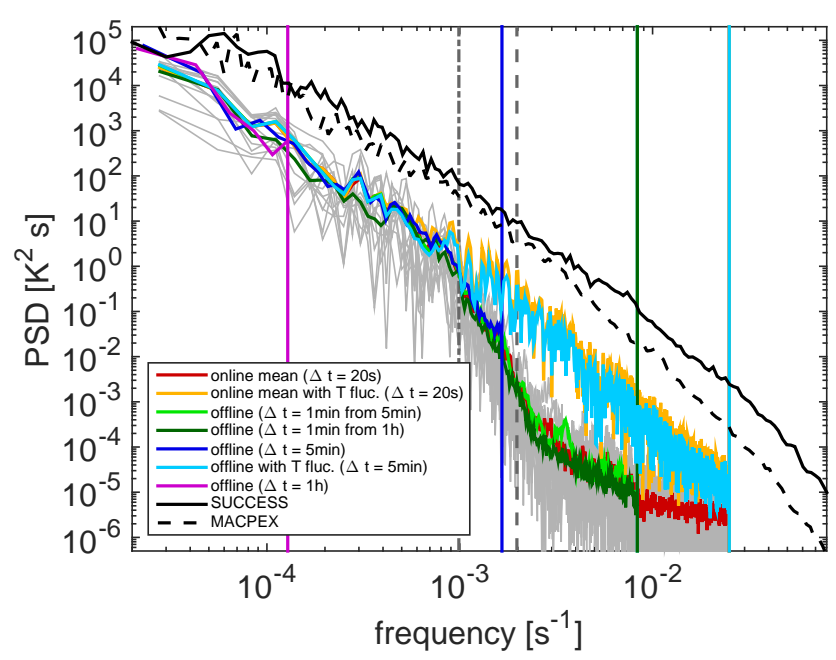

Figure 3. Power spectral densities (PSDs) of the temperature calculated for trajectories arriving above Jungfraujoch at 09:00 UTC at $10.0-11.5 \mathrm{~km}$, where the cirrus cloud was observed by the lidar. Grey lines: PSDs of individual 20s online trajectories. Red line: average of the online trajectories. Orange: online trajectory with superimposed temperature fluctuations. Light green: offline trajectories based on 5 min model output, interpolated to 1 min resolution. Dark green: based on $1 \mathrm{~h}$ model output, interpolated to $1 \mathrm{~min}$. Dark blue: offline trajectories based on 5 min COSMO- 2 model output. Light blue: offline trajectories based on 5 min COSMO2 model output with superimposed small-scale temperature fluctuations. Purple: offline trajectories based on $1 \mathrm{~h}$ model output. Coloured vertical lines: Nyquist frequency for each specific temporal resolution. Black solid curve: PSD derived from aircraft data sampled during the SUCCESS campaign. Black dashed curve: same but for the MACPEX campaign. Dashed vertical line: maximum frequency that can be resolved on the COSMO-Model grid given the finite horizontal resolution and the mean horizontal velocity along the trajectories $\left(f_{\max }=17.4 \mathrm{~m} \mathrm{~s}^{-1} /(4 \times 2.2 \mathrm{~km}) \approx 2 \times 10^{-3} \mathrm{~s}^{-1}\right)$. Dashed-dotted vertical line: cut-off frequency using $8 \Delta x$ as effective model resolution.

by using the wind fields at each Eulerian model time step for the trajectory calculation (Miltenberger et al., 2013).

The mean power spectral density of temperature fluctuations is shown in Fig. 3 for trajectories based on wind fields at a temporal resolution of $20 \mathrm{~s}$ (red curve), $5 \mathrm{~min}$ (blue curve) and $1 \mathrm{~h}$ (green curve). Displayed are also trajectories with a temporal resolution of $1 \mathrm{~min}$, which have been interpolated from $5 \mathrm{~min}$ and $1 \mathrm{~h}$ COSMO- 2 model output. While the PSDs are overall very similar, it is clear that increasing the temporal resolution increases the spectrum of resolvable waves to larger frequencies. As discussed above, waves with a wavelength smaller than $4 \Delta x$ cannot be resolved on the Eulerian grid, which corresponds to wave frequencies higher than about $2 \times 10^{-3} \mathrm{~s}^{-1}$ using the average horizontal velocity of $17.4 \mathrm{~m} \mathrm{~s}^{-1}$ along the trajectories (vertical black dasheddotted line in Fig. 3). Waves with slightly larger wavelength also suffer from amplitude and phase errors in the Eulerian 


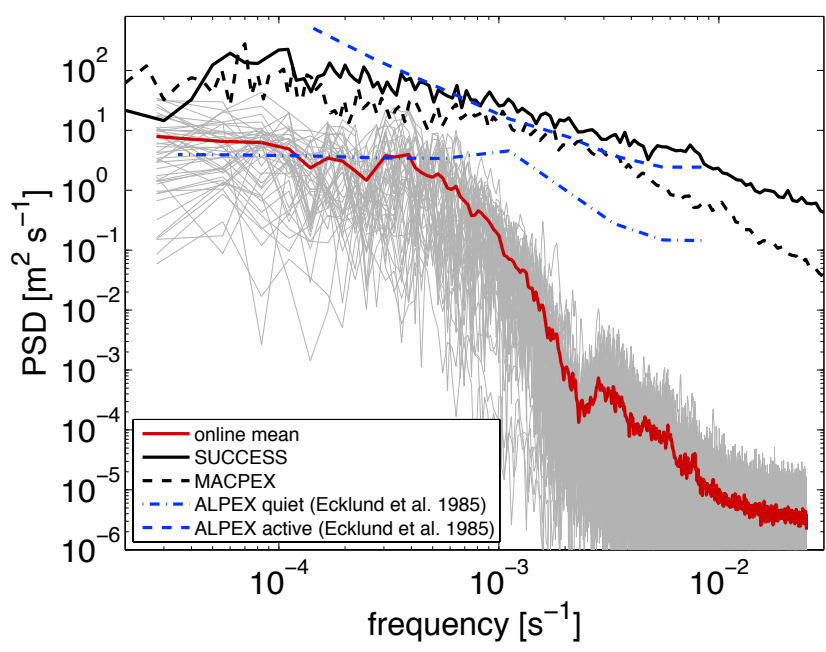

Figure 4. Power spectral density (PSD) of the vertical wind calculated from online trajectories (grey) passing above Jungfraujoch at 09:00 UTC between 10.0 and $11.5 \mathrm{~km}$. Red curve: average of online trajectories. Solid and dashed black lines: PSDs of vertical velocities measured during SUCCESS (Toon et al., 1998) and MACPEX (Rollins et al., 2014), respectively. Blue dashed and dashed-dotted lines: data from the ALPEX campaign for active and quiet days, respectively (Kuettner, 1981).

model up to about wavelengths of $8 \Delta x$ (corresponding frequency indicated by vertical dashed line in Fig. 3). From comparison of these limiting frequencies to the frequencies resolved in the trajectory data, it becomes clear that an hourly temporal resolution is completely insufficient to capture the temperature variability represented on the Eulerian grid (only frequencies up to about $10^{-4} \mathrm{~s}^{-1}$ can be resolved). In contrast, trajectories based on 5 min wind field data are able to represent almost all frequencies that can be represented on the Eulerian grid. Online trajectories cover even a larger frequency range. Accordingly, trajectory data based on NWP simulations with $\Delta x=2.2 \mathrm{~km}$ should be used at a temporal resolution of at least $5 \mathrm{~min}$.

For comparison to our model data we use the highresolution temperature data from the SUCCESS campaign, which took place over the central and western United States (Toon et al., 1998), and from the MACPEX campaign, which took place mainly over the Gulf of Mexico and the southeastern United States (Rollins et al., 2014). Both campaigns show significantly higher intensity for all frequencies, as will be further analysed below.

\subsection{Vertical velocity fluctuations}

A different, though related, question is the quality of the representation of small-scale fluctuations in the Eulerian model itself. This can be assessed by comparing the PSD of the model to PSDs measured during field campaigns in the upper troposphere. For comparison to our model data we use the vertical velocity data from SUCCESS (Toon et al., 1998) and MACPEX (Rollins et al., 2014) and furthermore from the ALPEX campaign carried out over the Alps (Kuettner, 1981). In a dry atmosphere the PSD of vertical velocities is directly linked to the occurring cooling rates by the dry adiabatic lapse rate; however, it is not directly related to the temperature PSD. The PSDs of the vertical velocity from SUCCESS, MACPEX, ALPEX and our COSMO-2 model simulation are shown in Fig. 4. The PSDs of the model simulation and the SUCCESS/MACPEX data show a very different power density even for very low frequencies, which should not be affected by the grid resolution of the model: the COSMO-2 model shows an almost constant PSD of $5 \mathrm{~m}^{2} \mathrm{~s}^{-1}$ for frequencies between $10^{-3}$ and $10^{-4} \mathrm{~s}^{-1}$, whereas the PSDs during SUCCESS and MACPEX varied between 10 and $100 \mathrm{~m}^{2} \mathrm{~s}^{-1}$ for the same frequency range. To understand the differences in the mesoscale range it is important to note that the model simulations and the SUCCESS and MACPEX measurements took place at different geographic locations and under different meteorological conditions. Mesoscale gravity waves may be excited by a number of different phenomena, including flow over topography, fronts, convection, large wind shear and jet streams (e.g. Nastrom et al., 1992; Fritts et al., 1992), and their vertical propagation depends on the state of the atmosphere, particularly the low-level stability (e.g. Nastrom et al., 1992). The spread between the power spectral densities observed during SUCCESS and MACPEX and those simulated for the cirrus case study corresponds to the variation in the PSD observed by Ecklund et al. (1985) for different meteorological situations during ALPEX. The PSDs observed during ALPEX for active and quite days are shown by the blue lines in Fig. 4. Active days have been characterized by strong surface winds (mistral), while the horizontal wind velocities are rather small during quiet days. MACPEX and SUCCESS PSDs resemble the ALPEX PSD during active days. Conversely, the low-frequency PSD of the COSMO-2 model resembles the PSD for quiet days during the ALPEX campaign. This resemblance agrees with the meteorological situation over central Europe, which on 22 November 2011 was dominated by a high-pressure system over eastern Europe.

To further assess the representation of vertical velocities $w$ in the COSMO-2 model, we investigated 71 balloon soundings conducted from Payerne and the vicinity of Zurich in the years 2010-2014 (see green dashed histogram in Fig. 5). We follow the work by Gallice et al. (2011), who showed that information on air vertical motion, $w$, can be derived from the ascent rate of sounding balloons. The deviation of the observed ascent of a sounding balloon from the one expected in vertically quiet air, as derived from a detailed treatment of the balloon motion, is caused by the vertical motion of the air $(w) . w$ can be estimated in a much simplified manner by subtracting a $500 \mathrm{~s}$ running mean (boxcar over 500 onesecond GPS measurements), which approximately represents the ascent of the balloon in quiet air (Cirisan et al., 2014), from the original ascent data of the sounding balloons. We 
cannot derive PSDs from sonde measurements since sondes measure the vertical wind only along quasi-vertical paths in very limited regions. Rather, for comparison we constructed a COSMO-2-based climatology of the squared vertical velocity amplitudes $w^{2}$ over the Alpine region for the years 20102014. For this we used hourly domain-averaged (COSMO-2, i.e. Alpine region) values of $w^{2}$ at altitudes between approximately 7 and $9 \mathrm{~km}$. Both data sets are depicted together with the SUCCESS and the MACPEX campaign data in Fig. 5. $w^{2}$ values derived from the COSMO-2 analysis and the balloon sounding agree very well, showing $w^{2}$ in the range $10^{-3}$ to $2 \mathrm{~m}^{2} \mathrm{~s}^{-2}$. This range corresponds very well to previous observational data reporting $w^{2}$ between 0.005 and $0.4 \mathrm{~m}^{2} \mathrm{~s}^{-2}$ (Ecklund et al., 1986; Gage et al., 1986). In contrast, only $w^{2}$ values larger than about $0.02 \mathrm{~m}^{2} \mathrm{~s}^{-2}$ were observed during the SUCCESS and MACPEX campaigns. The reason for this discrepancy remains unclear, but it is possible that SUCCESS and MACPEX sampled mainly active periods, while the balloon data set covers quiet and active days.

We conclude from this comparison that the COSMO-2 model is able to simulate a reasonable climatological distribution of $w^{2}$, though $w^{2}$ of individual days may be underestimated due to the missing sub-grid-scale vertical motions. The power density at the unresolved frequencies higher than $10^{-3} \mathrm{~s}^{-1}$ is much lower than at smaller frequencies and hence has only a small impact on the $w^{2}$ distribution in Fig. 5. A future study should perform an in-depth evaluation of the model performance on a day-by-day basis using vertical velocity measurements. The mean $w^{2}$ over the Alpine region for the day thoroughly analysed in this paper is indicated by an orange line in Fig. 5: compared to the climatological distribution, this day clearly belongs to the very quiet days. In addition, $w^{2}$ of an active day is shown by the yellow line. This active day is further discussed in the Appendix.

The comparison of the $w$ PSD from the COSMO-2 model simulations and from ALPEX suggests that the spectral densities up to a frequency of about $6-8 \times 10^{-4} \mathrm{~s}^{-1}$ are well represented along online trajectories. This is approximately the frequency range in which power density biases due to the spatial resolution of the COSMO- 2 model would be expected to be small. Higher frequency fluctuations, which may affect cirrus cloud formation, are, however, not represented in the trajectory data and have to be added artificially. To tackle this issue, we take an approach that is similar to previous studies dealing with this issue (e.g. Hoyle et al., 2005; Brabec et al., 2012; Rolf et al., 2012; Engel et al., 2013; Cirisan et al., 2014): High-frequency temperature fluctuations which are constructed from a measured PSD are superimposed at random phase on the trajectory's temperature time series. To construct proper small-scale temperature fluctuations the mean PSD of the MACPEX and SUCCESS campaign is fitted to the power spectral density from the trajectory data at a frequency of $8 \times 10^{-4} \mathrm{~s}^{-1}$ (Fig. 3). The high-frequency part of this scaled PSD is then Fourier-transformed using 20 different random-phase time series, resulting in 20 different

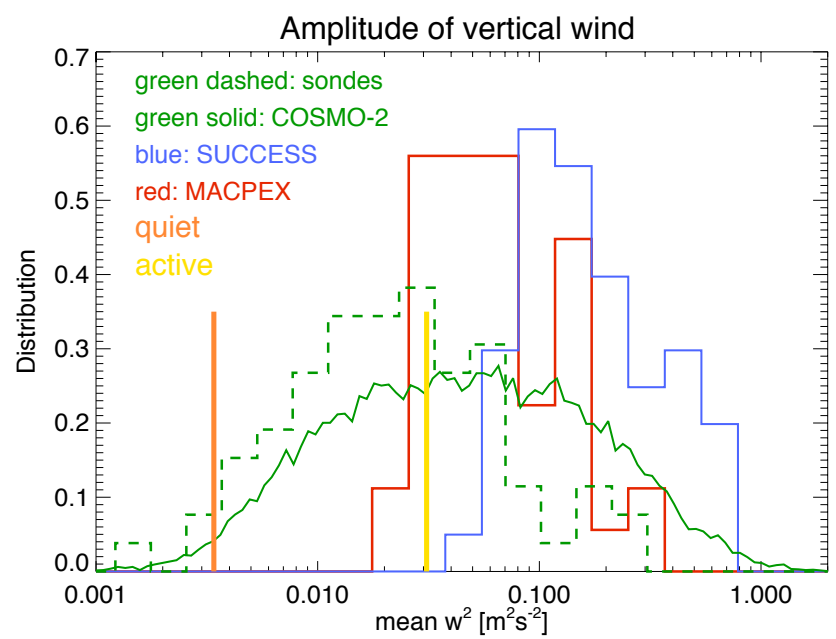

Figure 5. Normalized distribution (d $\left.f / \mathrm{d} \ln w^{2}\right)$ of hourly mean values of $w^{2}$. Blue and red: aircraft measurements during SUCCESS and MACPEX, respectively. Solid green line: daily mean $w^{2}$ in the COSMO-2 analysis for the Alpine region for the time period from 2010 to 2014. Dashed green line: distribution of vertical winds for 71 balloon soundings from Zurich and Payerne (Switzerland). Orange bar: mean vertical wind along the online trajectories on 22 November 2011. Yellow bar: mean $w^{2}$ along offline trajectories on an active day analysed in Appendix A.

small-scale temperature series, which are subsequently superimposed on the original temperature series. The resulting PSD of temperature along the trajectories is shown in Fig. 3 by the orange (online trajectories) and light blue line (offline trajectories based on 5 min wind field data).

\section{Cirrus cloud modelling}

Using the microphysical box model ZOMM forced by time series of $(p, T)$ from the introduced trajectory data sets, we assess the implications of temporal resolution (Sect. 4.1), small-scale temperature fluctuations (Sect. 4.2), initial moisture content (Sect. 4.4) and the number of available ice nuclei (Sect. 4.6) for the modelled cirrus cloud properties. We evaluate the modelling results against lidar measurements of extinction profiles above Jungfraujoch.

\subsection{Influence of the temporal resolution of the trajectory data}

The ice water content and ice crystal number density simulated by ZOMM are shown in Figs. 6 and 7 for different trajectory data sets: the upper row shows simulations results using directly the online trajectory data (right panel) and offline trajectories at a temporal resolution of 1 min (middle panel) and $5 \mathrm{~min}$ (left panel). Both offline trajectory data sets have been computed with wind field data at a temporal resolution of $5 \mathrm{~min}$. The different lines in each panel display the vertical 


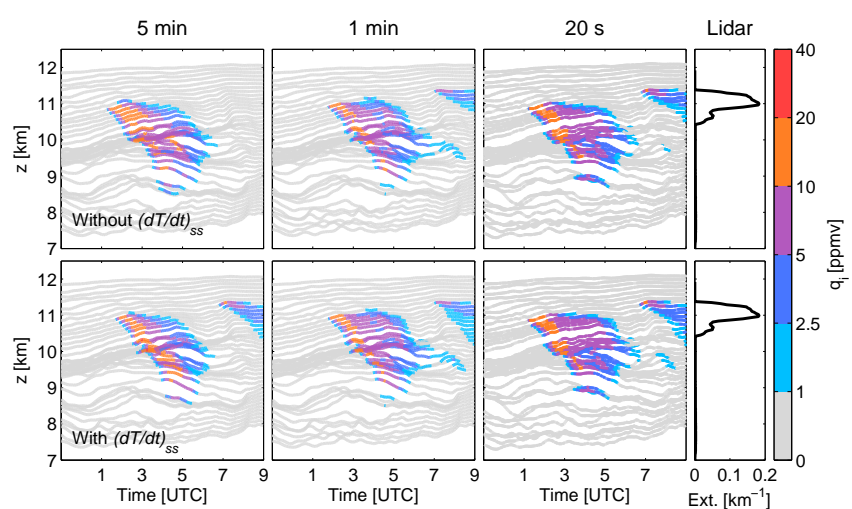

Figure 6. Vertical position of the trajectories displayed as a function of the time prior to their arrival at Jungfraujoch at 09:00 UTC (right edge of each panel). Colour coding: ZOMM simulations of the ice water content $q_{\mathrm{i}}$ in ppmv. First column: offline trajectories with a temporal resolution of $5 \mathrm{~min}$. Second column: offline trajectories with a temporal resolution of $1 \mathrm{~min}$. Third column: online trajectories (20 s temporal resolution). Upper row: simulations along trajectories based directly on COSMO-2 model output. Lower row: simulations with small-scale temperature fluctuations superimposed on the original temperature time series. All simulations: assuming nucleation to be only homogeneous, and with initial humidity reduced by $5 \%$ with respect to the COSMO-2 model value.

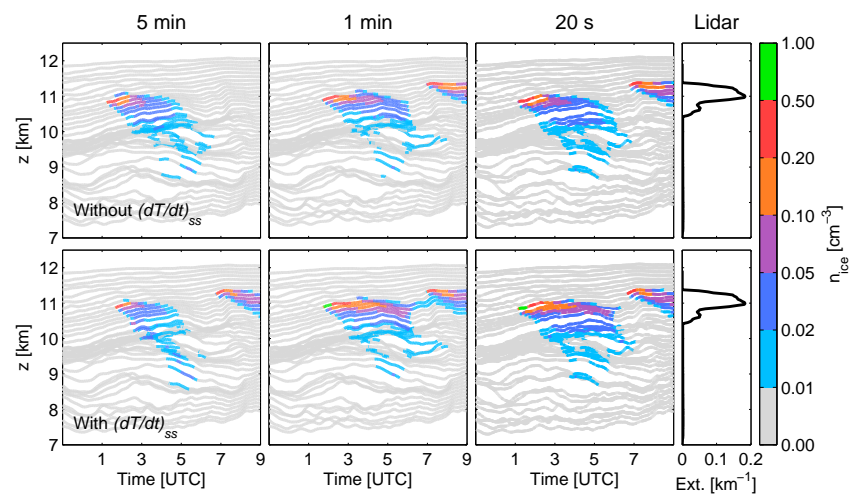

Figure 7. Same as Fig. 6 but for the ice crystal number density $n_{\text {ice }}$ in $\mathrm{cm}^{-3}$ (colour coding).

position of each trajectories in the $10 \mathrm{~h}$ prior to their arrival at Jungfraujoch (at the right edge of each panel), while the colour coding shows the modelled ice water content (Fig. 6) or the ice crystal number density (Fig. 7). Both figures show results from simulations with homogeneous nucleation only and a slightly reduced initial moisture content compared to the COSMO-2 model data (95\%), as no cirrus cloud occurs above Jungfraujoch in simulations using the unmodified initial moisture content. The lower rows in both figures show simulations with superimposed small-scale temperature fluctuations and will be discussed in the next section.

All simulations display a first nucleation event about $7-8 \mathrm{~h}$ before the arrival at Jungfraujoch, but all ice particles formed in this event sediment out before the air parcel reaches Jungfraujoch (Fig. 6). In the model runs using trajectories with a temporal resolution of $1 \mathrm{~min}$ and $20 \mathrm{~s}$ (left and middle panel), a second nucleation occurs about $2 \mathrm{~h}$ before the arrival at Jungfraujoch. The ice crystals nucleated in this event reach Jungfraujoch at altitudes between 10.5 and $11.5 \mathrm{~km}$, which corresponds to the observed cloud height in the lidar measurements (Fig. 1), as also shown by the rightmost panels in Figs. 6 and 7. The ice water content and the ice crystal number density is slightly larger in simulations based on online trajectories (labelled $20 \mathrm{~s}$ in Figs. 6 and 7). A closer examination of this nucleation event shows that the nucleation occurs slightly earlier in the online trajectories data set. Accordingly, the cooling rates are slightly higher and the nucleation events lasts longer due to a longer time period in the updraft.

The reason for these differences is likely the small differences in the removal of water vapour after the first nucleation event and slight temporal shifts in the ascent of the parcel related to the different temporal resolution of the wind fields. The important second nucleation event does not occur in simulations using trajectories at a temporal resolution of $5 \mathrm{~min}$.

\section{SAL metric}

The extinction profiles from the three simulations are shown by the blue lines in Fig. 9. The model extinction profiles compare well with the extinction profile retrieved from the lidar measurement (black lines) in terms of the amplitude as well as in the vertical positioning of the cloud for trajectory data at a temporal resolution of $20 \mathrm{~s}$ and $1 \mathrm{~min}$ (Fig. $9 \mathrm{~b}$ and c). Accordingly, the location, amplitude and structure error in the SAL metric are small for all simulations (see orange upward-pointing triangles in Fig. 10 below). In contrast, no cloud forms above Jungfraujoch in simulations with trajectories with $5 \mathrm{~min}$ temporal resolution (Fig. 9a).

\subsection{Influence of small-scale temperature fluctuations}

Small-scale temperature fluctuations, which are not resolved in the NWP model, can modify the cooling rate at the time of nucleation and therefore alter the number of nucleated ice crystals in case of a homogeneous nucleation event. To assess the impact of these temperature fluctuations we superimposed additional temperature fluctuations which are derived from measurements during the SUCCESS and MACPEX campaigns on the original trajectory temperature series (Sects. 3.2 and 3.3). The influence of this modification of the temperature series on the microphysical evolution can be seen by comparing the upper and lower rows of Figs. 6 and 7. The influence on the corresponding extinction profile is shown by the grey lines in Figs. 8 and 9 (compare with green line). From these figures it is obvious that the added temperature fluctuation have a significant impact on the modelled extinction profiles if trajectories are used at 

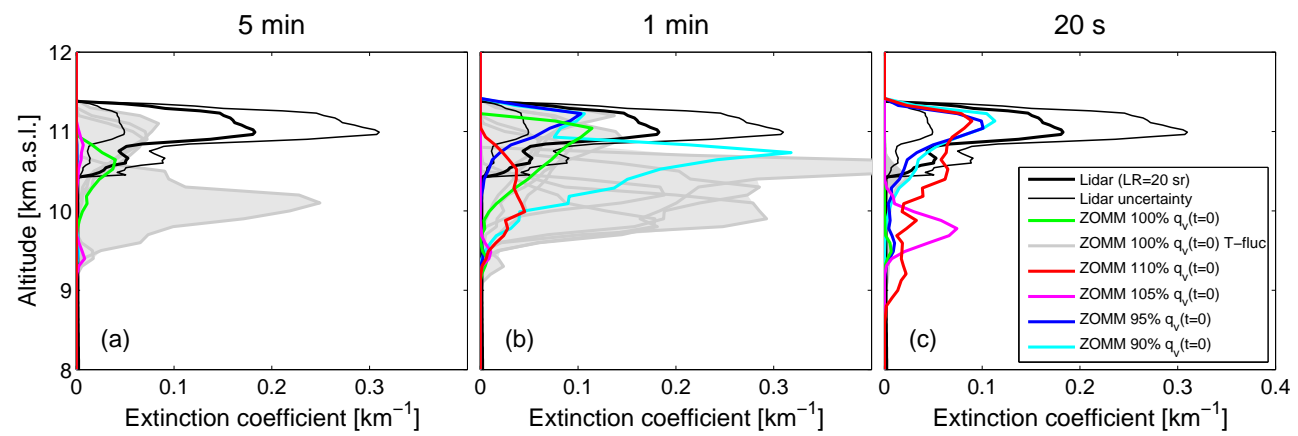

Figure 8. Extinction profiles above Jungfraujoch at 09:00 UTC on 22 November 2011 calculated by ZOMM along offline trajectories with a temporal resolution of $5 \mathrm{~min}$ (a) and $1 \mathrm{~min}$ (b), and along online trajectories with a temporal resolution of $20 \mathrm{~s}$ (c). All simulations assume homogeneous nucleation only. Thick black line: measured lidar profile. Thin black lines: measurement uncertainty, i.e. uncertainties in the lidar signal, the assumption of lidar ratio and the molecular properties retrieved from COSMO-2 analysis data. Different colours: calculated profiles for simulations with modified initial specific humidities $q_{v}(t=0)$ of the trajectories. Grey lines: simulations of the reference run $\left(100 \% q_{v}(t=0)\right)$ with 20 different sets of superimposed small-scale temperature fluctuations.
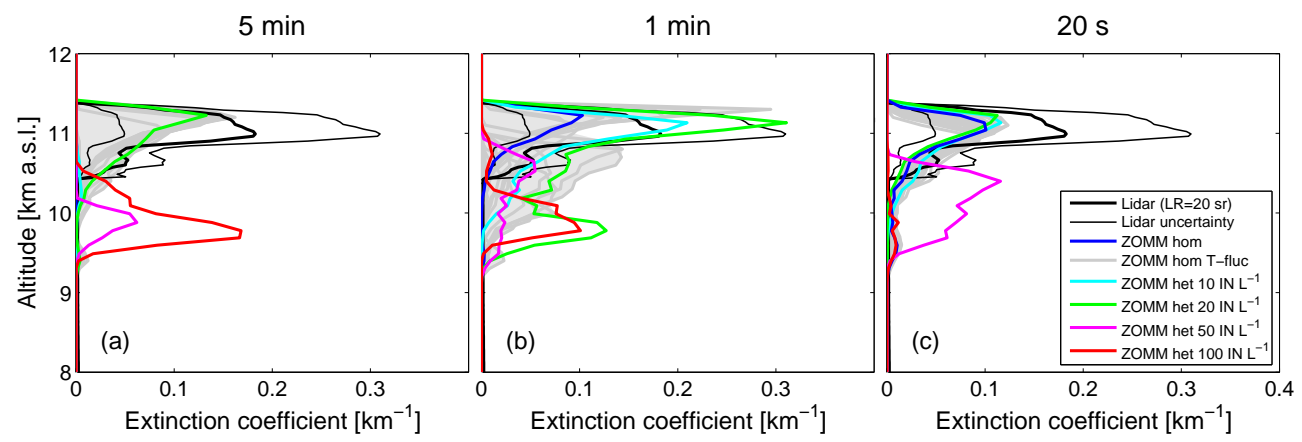

Figure 9. Extinction profiles as in Fig. 8 but assuming different ice nuclei number densities and an initial humidity $q_{v}(t=0)$ of $5 \%$ lower than the value derived from the COSMO-2 model. Reference run (without heterogeneous ice nucleation): identical to the simulation shown by the cyan line in Fig. 8. Grey curves: simulations of homogeneous run with superimposed small-scale temperature fluctuations.

minute-scale temporal resolution. They can modify the amplitude of the extinction signal as well as the vertical position of the cloud. However, for online trajectories the superimposed temperature fluctuations have no significant influence on the modelled extinction profile (Fig. 9c). The physical reason for the strongly different impact of superimposed temperature fluctuations for online trajectories and $1 \mathrm{~min}$ trajectories is not evident from our analysis as the temperature PSDs, and the initial conditions for both trajectory sets are almost identical. This issue needs to be addressed in a future study.

\subsection{SAL metric}

In terms of the SAL metric, the influence of the additionally superimposed small-scale temperature fluctuations particularly influences the amplitude of the modelled extinction profile (open and filled symbols in Fig. 10 below). In general, the location and shape of the cloud (L component) is not positively affected by adding small-scale temperature fluctuations. Consistent with the previous discussion, the impact is largest for simulations with a small temporal resolution of the trajectory data.

\subsection{Influence of variations in the initial moisture content}

As it is known that the moisture content in weather prediction models is very uncertain in the upper troposphere (Kunz et al., 2014), simulations with different specific humidity at the trajectory starting points were performed. We used initial humidities between 90 and $110 \%$ of the values calculated by the COSMO-2 model. The extinctions resulting from these sensitivity runs are shown in Fig. 8 (assuming homogeneous nucleation only). Offline trajectories with a temporal resolution of 5 and $1 \mathrm{~min}$ are displayed in panels a and b. Simulations using online trajectories are displayed in panel c. For the simulations using online trajectories, all runs except the 100 and $105 \%$ cases display a cloud at the right altitude with very good agreement with the measured extinction profiles. For the $1 \mathrm{~min}$ offline trajectories, enhanced humidity produces clouds at altitudes that are too low because of nu- 

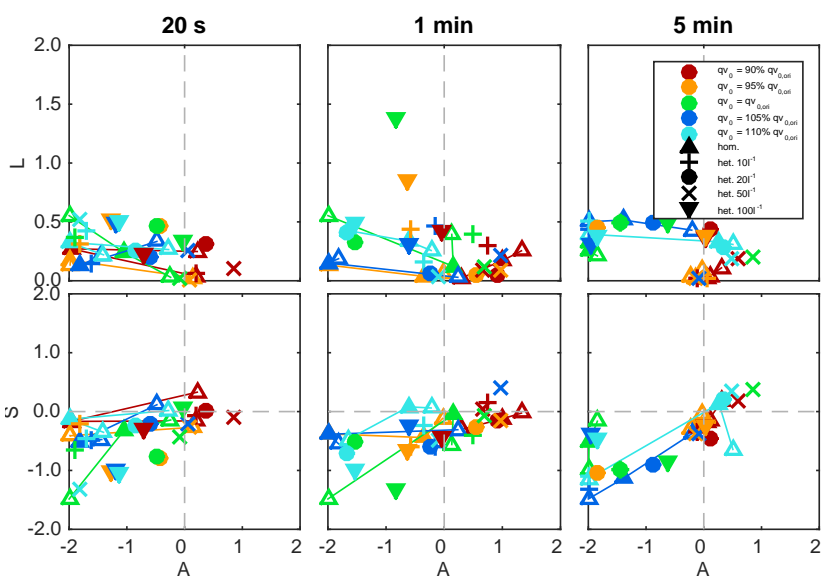

Figure 10. SAL for ZOMM simulations with modified initial moisture content (colours), different nucleation modes (filled symbols) and with additional superimposed small-scale temperature fluctuations (coloured lines and open symbols). Open symbols: best and worst prediction in terms of the SAL metric from the 20 runs with different superimposed small-scale temperature fluctuations. Left column: SAL for offline trajectories with a temporal resolution of 5 min. Middle column: SAL for offline trajectories with a temporal resolution of $1 \mathrm{~min}$. Right column: SAL for online trajectories.

cleation occurring too early and subsequent sedimentation of the formed ice crystals.

For the offline trajectories with a temporal resolution of $5 \mathrm{~min}$, the variation in the initial humidity leads in almost all cases to a disappearance of the cloud (Fig. 8a). Using offline trajectories with a temporal resolution of $1 \mathrm{~min}$ (Fig. $8 \mathrm{~b}$ ) results in profiles similar to the ones using online trajectories.

\subsection{SAL metric}

The conclusion that increasing temporal resolution of the trajectory data leads to better matches between the observed and modelled extinction profiles and to decreasing importance of the unresolved small-scale temperature fluctuations holds for any initial humidity modification investigated. However, the differences between simulations with different initial humidities are very large. While all terms in the SAL metric are influenced by changes in the initial humidity, the impact on the cloud location is particularly large (Figs. 8 and 10).

\subsection{Influence of the ice nuclei number density}

An additional uncertainty in modelling the microphysical evolution of cirrus clouds is the potential presence of ice nuclei (IN). These can affect the microphysical evolution as they influence the supersaturation and temperature required for nucleation. Further, IN can lead to a reduction of the nucleated ice crystal number density, which may affect the sedimentation velocity of the ice crystals and hence the total water content of the respective air parcel.
We performed simulations including heterogeneous nucleation on different IN concentrations. Significant differences can be observed between the results from these simulations even for a single trajectory data set (Fig. 9). The general finding is that simulations with 0,10 or $20 \mathrm{IN} \mathrm{L}^{-1}$ show good agreement with observations, with differences amongst each other smaller than uncertainties due to unresolved smallscale temperature fluctuations and smaller than uncertainties in the observations. Conversely, simulations with more than $20 \mathrm{IN} \mathrm{L}^{-1}$ do not provide good agreement with observations.

In the case of online trajectories $(20 \mathrm{~s})$ the almost complete loss of extinction for IN concentration of $100 \mathrm{~L}^{-1}$ is due to fast evaporation of ice crystals once they enter the subsaturated region below about $10 \mathrm{~km}$ a.s.l. The evaporation timescale strongly depends on the relative humidity, which is likely not very robust in our simulations due to the effect of previous nucleation events on the moisture content on lower level parcels. As discussed in Sect. 3.1, these modifications of the moisture content depend on the treatment of sedimentation and assumptions on temporal and horizontal alignment of the parcels. These assumptions may not hold for the present case due to the comparably large horizontal spread of trajectories. For the 1 and 5 min offline trajectories the evaporation is much slower, leading to larger extinction values between 9.5 and $10 \mathrm{~km}$ altitude (red lines in Fig. 9a, b). Slight differences in the vertical paths between the trajectory data sets contribute additionally to the variation in the evaporation timescale, as these also impact the relative humidity.

The similarity of the extinction profiles for the simulations with only homogeneous nucleation and those with low IN concentrations is linked to the very fast sedimentation of the ice crystals forming in the early phase of the simulated $10 \mathrm{~h}$ time period. The very fast sedimentation of the ice crystals allows for multiple nucleation events along the trajectory, and these gradually remove all IN from the air parcel. Hence, the last nucleation leading to the cloud present at arrival above Jungfraujoch is formed exclusively by homogeneous nucleation.

The simulations using offline trajectories at $5 \mathrm{~min}$ resolution (Fig. 9a) show a very different behaviour for the simulation with $10 \mathrm{~L}^{-1}$ : the formed cloud sediments out before reaching Jungfraujoch and no second nucleation event occurs. Using the offline trajectories without superimposing temperature fluctuations, the model produces a cloud only when assuming an IN concentration of $20 \mathrm{~L}^{-1}$. For simulations using IN concentrations larger than $50 \mathrm{~L}^{-1}$, clouds only exist at lower levels. However, if we use offline trajectories with a temporal resolution of $1 \mathrm{~min}$, the model results again resemble those using online trajectories (Fig. 9b).

\section{SAL metric}

While there is clearly a strong impact of the assumed nucleation mode and the IN number density on the microphysical 
evolution, its influence may vary in a non-linear fashion with other uncertainties, such as variations in the initial humidity. This also becomes clear from the SAL analysis shown in Fig. 10: the comparison of different symbols with the same colour indicates no consistent improvement for a single nucleation mode in any of the three error components.

Similar to the experiments with modified initial moisture content, the assumed IN number density does not affect the conclusions on the importance of small-scale temperature fluctuations and increasing temporal resolution of the trajectory data. Adding small IN number densities $\left(\leq 20 \mathrm{~L}^{-1}\right)$ has little effect on the simulated extinction profiles for trajectories with a high temporal resolution, while adding $50 \mathrm{~L}^{-1}$ or more significantly deteriorates the position, amplitude and structure of the cloud (Figs. 9 and 10).

\section{Conclusions}

An analysis of the uncertainties involved in Lagrangian cirrus modelling has been presented. The investigated sensitivities include the effects of (i) the temporal resolution of the trajectory data and of the underlying wind fields ( $20 \mathrm{~s}$ to $1 \mathrm{~h}$ ), (ii) the superposition of unresolved small-scale temperature fluctuations, (iii) small perturbations to the specific humidity at the trajectory starting points $( \pm 10 \%)$, and (iv) different ice nuclei concentrations.

The temporal resolution of the wind field data has a pronounced impact on vertical velocities and therefore the temperature variability captured in the trajectory data. To capture most of the variability that is represented in NWP models with a horizontal grid spacing of $2.2 \mathrm{~km}$, trajectory data should be used at least at a 5 min temporal resolution. For the cirrus cloud investigated in this study, the modelled extinction profile matches very well with the observations if trajectory data are used at a temporal resolution of $1 \mathrm{~min}$ or higher and wind field data at a resolution of $5 \mathrm{~min}$ or higher.

Vertical velocity fluctuations occurring at highest frequencies are not resolved in state-of-the-art numerical weather prediction model due to the finite grid resolution. Yet, these high-frequency fluctuations may alter the cooling rates locally and thus influence ice nucleation events. To investigate the impact of the unresolved fluctuations, we superimposed the missing frequencies of the temperature fluctuations, which are derived from observed power spectral densities of temperature fluctuations from the SUCCESS and MACPEX campaigns, onto the original temperature series. (The observational PSD are scaled to the model PSD at the cut-off frequency to obtain a continuous PSD.) The influence of these superimposed temperature fluctuations is significant for trajectories with a temporal resolution of $5 \mathrm{~min}$ and successively decreases for trajectories with a temporal resolution of $1 \mathrm{~min}$ and $20 \mathrm{~s}$. While the modelled extinction profile for trajectory data at $20 \mathrm{~s}$ temporal resolution matches the observations very well even without superimposed small- scale temperature fluctuations, the superposition is essential for modelling of the cirrus cloud along trajectory data with at temporal resolution of 1 or $5 \mathrm{~min}$. In the Appendix we show that the imposed small-scale temperature fluctuations have a significant impact on the cirrus clouds both for the quiet and active periods, i.e. with strongly different $w^{2}$, using $1 \mathrm{~h}$ wind data and 1 min trajectory temporal resolution (Fig. A4). Even for a regional model with $2.2 \mathrm{~km}$ resolution, the superposition of small-scale temperature fluctuation should be considered in cirrus simulations.

In order to obtain physically meaningful small-scale temperature fluctuations, some assumptions about the shape and amplitude of the power spectral density of the vertical velocity and temperature are required. A comparison of the PSD and amplitudes of the vertical velocity predicted by the COSMO-2 model for the present case study shows significant differences to observational data from the SUCCESS and MACPEX campaigns, which have been used previously to superimpose small-scale temperature fluctuations. Significant differences in the wave energy occur even for lowfrequency waves with wavelength on the order of $100 \mathrm{~km}$, which should not be affected by the grid resolution. However, the modelled PSD agrees well with those observed during quiet days in the ALPEX campaign. Further indication of a large day-to-day variability of $w^{2}$ is provided by the analysis of balloon sounding data from the Alpine region. A climatological analysis of $w^{2}$ in the COSMO-2 analysis suggests that the model can capture the entire range of observed $w^{2}$. However, future studies should perform an in-depth evaluation of the model capability to predict the vertical velocity PSD for different regions and large-scale meteorological conditions.

The specific moisture content at the starting point of each trajectory determines the absolute values of saturation with respect to ice. We observe significant changes in the modelled cirrus cloud properties and microphysical evolution if the initial specific humidity is varied by $\pm 10 \%$ of the model value. For high-resolution trajectory data (5 min or better), the sensitivity of the modelled cirrus cloud to perturbations in the parcel's humidity are generally larger than the sensitivity to small-scale temperature fluctuations.

Finally, for the cirrus cloud investigated in this study, only a weak sensitivity with respect to ice nuclei number density is found - i.e. very small changes of the modelled extinction profile occur if the ice nuclei number density is raised from 0 to $20 \mathrm{~L}^{-1}$. This insensitivity is related to the occurrence of two nucleation events along the trajectories, which leads to the sedimentational removal of ice nuclei by the first cloud. Conversely, if the ice nuclei number density is increased further to 50 or $100 \mathrm{~L}^{-1}$, the modelled extinction profile cannot reproduce the observation. The cirrus clouds either disappear completely or are located at much lower altitude than in the homogeneous case, as the fewer but larger ice particles sediment more quickly (see Fig. 9). Also, in a case with dynamically active conditions as treated in the Appendix, the calculated extinction coefficients using IN concentrations of 50 or 
$100 \mathrm{~L}^{-1}$ are too small compared to measurements (Fig. A4), even when small-scale temperature fluctuations are superimposed. Thus, heterogeneous ice number densities of $50 \mathrm{~L}^{-1}$ or more appear to be very unlikely. The major fraction of the ice particles originate from homogeneous nucleation.

Lagrangian cirrus cloud modelling shows large sensitivities to all investigated factors. However, the order of their importance can vary from case to case. The presented case study of an isolated temporally persistent cirrus cloud with rather small horizontal extent may only be representative for cirrus cloud formation under some specific conditions. In addition, the wave activity on the investigated day is clearly below the climatological average. Therefore we present a case with dynamically more active conditions in the Appendix. For the active day, the modelled cirrus clouds shows different responses to modifications of the initial humidity and the assumed ice nuclei number density: variations in both parameters lead in general to a variation in the optical thickness of the cloud, while they also affected the vertical location of the cloud on the quiet day. Similar to the quiet day, simulations with ice nuclei number density in excess of $20 \mathrm{~L}^{-1}$ are found to be inconsistent with the observations. The best match with the observed extinction profile is obtained for an increased initial moisture content. A high sensitivity of Lagrangian cirrus cloud modelling to initial humidity was also found by Dinh et al. (2015) in simulations for cirrus clouds in the tropical tropopause layer.
While the use of high-resolution trajectory data is shown to be mandatory for cirrus cloud modelling, there are significant uncertainties tied to the specific humidity and ice nuclei number density, turning cirrus cloud modelling into a challenging task with many non-linearly linked uncertainties. The representation of small-scale temperature fluctuations remains an issue for cirrus cloud modelling, particularly due to the large day-to-day variations in the wave activity, but the results presented here indicate that high-resolution numerical weather prediction models are capable to capture these variations. A careful consideration of these uncertainties is necessary before any conclusion about the formation of a cirrus cloud can be drawn. 


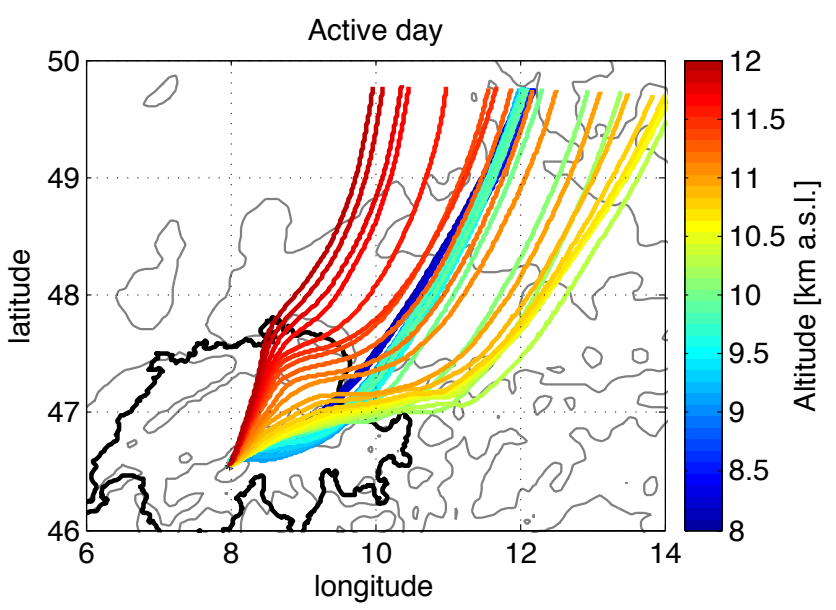

Figure A1. Path of the trajectories arriving at Jungfraujoch on 12 March 2012 at 03:00 UTC.

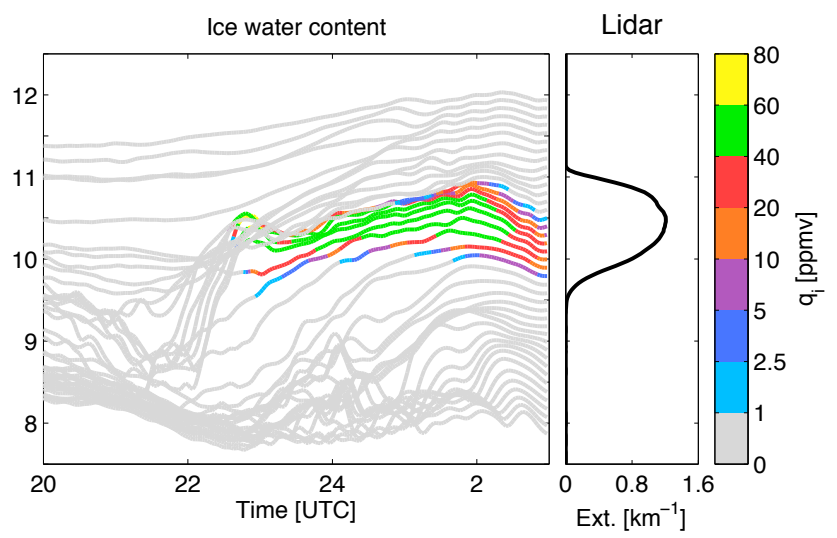

Figure A2. Ice water content from the ZOMM simulation along the trajectories.

\section{Appendix A: An active day}

A comparison of the vertical velocity distribution which is predicted by the COSMO-Model for the case study presented in this paper, shows significantly lower amplitudes than measurement data from either the SUCCESS or the MACPEX campaign (Figs. 4 and 5). As discussed in Sect. 3.3, this is likely related to the synoptic-scale situation over central Europe on this particular day. A statistical analysis of $w^{2}$ from 71 balloon soundings and the COSMO- 2 model analysis suggests a reasonable performance of the COSMO-2 model in a climatological sense (Fig. 5), but it remains unclear how the NWP models perform on a day with $w^{2}$ in the upper range indicated in Fig. 5. To analyse this further, we investigate 12 March 2012, which is an "active day" featuring a cirrus cloud above Jungfraujoch, and compare the wind fields from the COSMO-2 analysis at hourly resolution. Based on these wind fields, backward trajectories from Jungfraujoch were

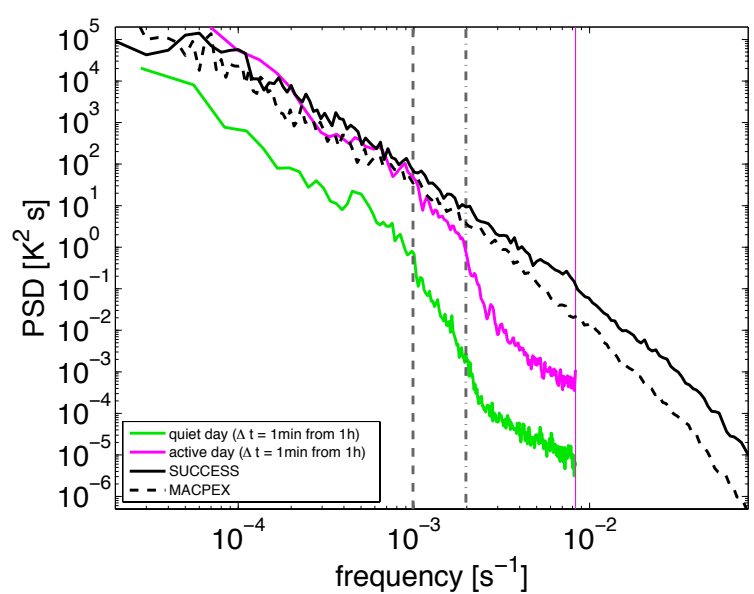

Figure A3. Power spectral density of the temperature calculated for trajectories arriving above Jungfraujoch as compared to the SUCCESS and MACPEX campaigns. Green line: PSD for quiet case on 22 November 2011 (identical to Fig. 3). Purple line: active case on 12 March 2012 discussed in the Appendix.

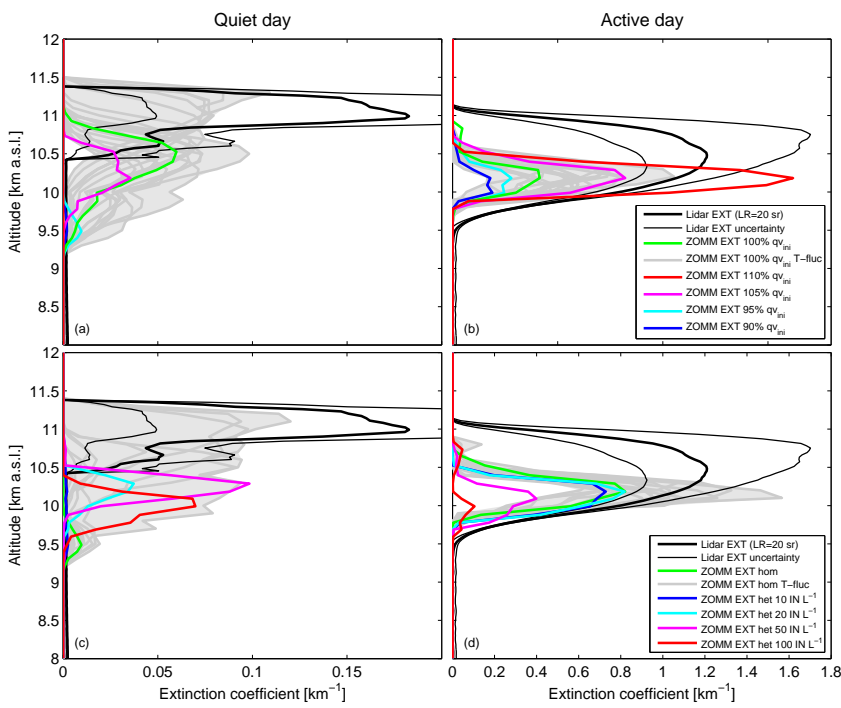

Figure A4. Extinction profiles above Jungfraujoch at 09:00 UTC on 22 November 2011 (quiet day) as well as 03:00 UTC on 12 March 2012 (active day) calculated from ZOMM simulations along trajectories with a temporal resolution of $1 \mathrm{~min}$. (a, b) Sensitivity to the initial humidity. (c, d) Sensitivity to the nucleation mode assuming 95 (quiet day) and 105\% (active) of the initial humidity derived from the COSMO-Model, respectively. Grey curves: simulations with superimposed small-scale temperature fluctuations.

calculated with LAGRANTO, using the LAGRANTO output with an interpolated 1 min temporal resolution.

During this active day, strong northeasterly flow against the Alps occurred (Fig. A1), which resulted in high gravity wave activity. The trajectories pass through a strong updraft zone at approximately 22:00 UTC (Fig. A2), which has a significant impact on the ice supersaturation and accord- 
ingly on the location of first ice nucleation. The PSD of temperature also shows significantly larger values at small frequencies than the quiet day analysed in the main part of the paper (Fig. A3). The power spectral density for this case agrees very well with the measurements from SUCCESS and MACPEX. This confirms that the amplitude of the temperature fluctuations at smaller frequencies is dependent on the wave activity (and the presence of convection), which varies with the synoptical-scale situation. The variation seems to be reasonably captured by high-resolution numerical models.

On the chosen active day a cirrus cloud was observed by the lidar on Jungfraujoch. The formation of this cirrus cloud was modelled with the ZOMM model based on the described trajectory data set. In these simulations the ice nucleation occurs always towards the end of the rapid ascent of the trajectories around 23:00 UTC (Fig. A2). About $1 \mathrm{~h}$ before reaching Jungfraujoch, the air parcels start to descend, which causes some of the nucleated ice particles to evaporate, particularly close to the cloud top. A maximum ice water content between 40 and $60 \mathrm{ppmv}$ is simulated for this case. As a comparison, maximum values of around $20 \mathrm{ppmv}$ were obtained for the quiet case. A comparison of the modelled and observed extinction profiles above Jungfraujoch is shown in Fig. A4: from this comparison it becomes evident that the upper cloud edge is not represented well in any simulation. While the superposition of small-scale temperature fluctuations, variation in the initial moisture content, and the ice nuclei number density significantly alter the absolute extinction value, they have little impact on the position of the modelled cirrus cloud. As the cirrus cloud formation in this case is largely determined by the strong ascent several hours before the arrival at Jungfraujoch, the small-scale temperature fluctuations have less impact on the extinction profile than on the quiet day. One effect that might explain the underestimated extinction in this case is the radiative dynamical effects, which were not considered in this study. Radiatively induced updrafts and water vapour flux convergence could help to maintain the cirrus cloud and produce an optically thicker cloud as well as a higher cloud top (Dinh et al., 2010; Schmidt and Garrett, 2013). It would be interesting to investigate whether the position error reduces if trajectories are calculated at a higher temporal resolution. The trajectory calculation should be particularly sensitive to the temporal resolution of the wind field data if large spatial and temporal gradients of the vertical velocity are present. 
Acknowledgements. We thank Daniel Leuenberger and André Walser from MeteoSwiss for their assistance in performing nudged COSMO-Model runs. In addition we thank the sounding team of MeteoSwiss in Payerne, in particular Gonzague Romanens, for conducting the COBALD soundings and providing operational sonde data. Thanks to Andrew Huisman and Laura Revell for proofreading and providing valuable input. This work was funded by GAW-CH as well as through ETH research grant ETH-38 11-1.

Edited by: T. Garrett

\section{References}

Ansmann, A., Wandinger, U., Riebesell, M., Weitkamp, C., and Michaelis, W.: Independent measurement of extinction and backscatter profiles in cirrus clouds by using a combined Raman elastic-backscatter Lidar, Appl. Opt., 31, 7113-7131, 1992.

Baldauf, M., Seifert, A., Förstner, J., Majewski, D., and Raschendorfer, M.: Operational convective-scale numerical weather prediction with the COSMO model: Description and Sensitivities, Mon. Weather Rev., 139, 3887-3905, 2011.

Bierdel, L., Friedrichs, P., and Bentzien, S.: Spatial kinetic energy spectra in the convection permitting limited-area NWP model COSMO-DE, Meteorol. Z., 21, 245-258, 2012.

Brabec, M., Wienhold, F. G., Luo, B. P., Vömel, H., Immler, F., Steiner, P., Hausammann, E., Weers, U., and Peter, T.: Particle backscatter and relative humidity measured across cirrus clouds and comparison with microphysical cirrus modelling, Atmos. Chem. Phys., 12, 9135-9148, doi:10.5194/acp-12-9135-2012, 2012.

Bunz, H., Benz, S., Gensch, I., and Krämer, M.: MAID: A model to simulate UT/LS aerosols and ice clouds, Environ. Res. Lett., 3, 035001, doi:10.1088/1748-9326/3/3/035001, 2008.

Chen, T., Rossow, W. B., and Zhang, Y.: Radiative effects of cloudtype variations, J. Climate, 13, 264-286, 2000.

Cirisan, A., Luo, B. P., Engel, I., Wienhold, F. G., Sprenger, M., Krieger, U. K., Weers, U., Romanens, G., Levrat, G., Jeannet, P., Ruffieux, D., Philipona, R., Calpini, B., Spichtinger, P., and Peter, T.: Balloon-borne match measurements of midlatitude cirrus clouds, Atmos. Chem. Phys., 14, 7341-7365, doi:10.5194/acp14-7341-2014, 2014.

Comstock, J. M., Lin, R.-F., Starr, D. O. C., and Yang, P.: Understanding ice supersaturation, particle growth, and number concentration in cirrus clouds, J. Geophys. Res., 113, D23211, doi:10.1029/2008JD010332, 2008.

Corti, T. and Peter, T.: A simple model for cloud radiative forcing, Atmos. Chem. Phys., 9, 5751-5758, doi:10.5194/acp-9-57512009, 2009.

Cziczo, D. J., Froyd, K. D., Hoose, C., Jensen, E. J., Diao, M., Zondlo, M. A., Smith, J. B., Twohy, C. H., and Murphy, D. M.: Clarifying the dominant sources and mechanisms of cirrus cloud formation, Science, 340, 1320-1324, doi:10.1126/science.1234145, 2013.

Cziczo, D. and Froyd, K. D.: Sampling the composition of cirrus ice residuals, Atmos. Res., 142, 15-31, 2014.

DeMott, P. J., Prenni, A. J., Liu, X., Kreidenweis, S. M., Petters, M. D., Twohy, C. H., Richardson, M. S., Eidhammer, T., and Rogers, D. C.: Predicting global atmospheric ice nuclei distributions and their impacts on climate, P. Natl. Acad. Sci. USA, 107, 1121711222, doi:10.1073/pnas.0910818107, 2010.

Dessler, A. E. and Yang, P.: The distribution of tropical thin cirrus clouds inferred from Terra MODIS data, J. Climate, 16, 1241-1247, doi:10.1175/1520 0442(2003)16<1241:TDOTTC>2.0.CO;2, 2003.

Dinh, T. P., Durran, D. R., and Ackerman, T. P.: Maintenance of tropical tropopause layer cirrus, J. Geophys. Res., 115, 21562202, doi:10.1029/2009JD012735, 2010.

Dinh, T., Podglajen, A., Hertzog, A., Legras, B., and Plougonven, R.: Effect of gravity wave temperature fluctuations on homogeneous ice nucleation in the tropical tropopause layer, Atmos. Chem. Phys. Discuss., 15, 8771-8799, doi:10.5194/acpd15-8771-2015, 2015.

Ebert, E. and Curry, J.: A parameterization of ice cloud optical properties for climate models, J. Geophys. Res., 97, 3831-3836, 1992.

Ecklund, W. L., Balsley, B. B., Carter, D. A., Riddle, A. C., Crochet, M., and Garello, R.: Observations of vertical motions in the troposphere and lower stratosphere using three closely spaced ST radars, Radio Sci., 20, 1196-1206, 1985.

Ecklund, W. L., Gage, K. S., Nastrom, G. D., and Balsley, B. B.: A preliminary climatology of the spectrum of vertical velocity observed by clear-air Doppler Radar, J. Climate Appl. Meteor., 25, 885-892, 1986.

Engel, I., Luo, B. P., Pitts, M. C., Poole, L. R., Hoyle, C. R., Grooß, J.-U., Dörnbrack, A., and Peter, T.: Heterogeneous formation of polar stratospheric clouds - Part 2: Nucleation of ice on synoptic scales, Atmos. Chem. Phys., 13, 10769-10785, doi:10.5194/acp13-10769-2013, 2013.

Fritts, D. C. and Nastrom, G. D.: Sources of mesoscale variability of gravity waves. Part II: Frontal, convective, and jet stream excitation, J. Atmos. Sci., 49, 111-127, 1992.

Fusina, F., Spichtinger, P., and Lohmann, U.: Impact of ice supersaturated regions and thin cirrus on radiation in the midlatitudes. J. Geophys. Res., 112, D24S14, doi:10.1029/2007JD008449, 2007.

Gage, K. S., Balsley, B. B., and Garello, R.: Comparisons of horizontal and vertical velocity spectra in the mesosphere, stratosphere and troposphere: observations and theory, Geophys. Res. Lett., 14, 1125-1128, 1986.

Gallice, A., Wienhold, F. G., Hoyle, C. R., Immler, F., and Peter, T.: Modeling the ascent of sounding balloons: derivation of the vertical air motion, Atmos. Meas. Tech., 4, 2235-2253, doi:10.5194/amt-4-2235-2011, 2011.

Haag, W. and Kärcher, B: The impact of aerosols and gravity waves on cirrus clouds at midlatitudes, J. Geophys. Res., 109, D12202, doi:10.1029/2004JD004579, 2004.

Hogan, R. J.: Fast Lidar and Radar multiple-scattering models. Part I: Small-angle scattering using the photon variance-covariance method, J. Atmos. Sci., 65, 3621-3635, doi:10.1175/2008JAS2642.1, 2008.

Hoyle, C. R., Luo, B. P., and Peter, T.: The origin of high ice crystal number densities in cirrus clouds, J. Atmos. Sci., 62, 2568-2579, 2005.

Jensen, E. J., Toon, O. B., Westphal, D. L., Kinne, S., and Heymsfield, A. J.: Microphysical modeling of cirrus 1. Comparison with 1986 FIRE IFO measurements, J. Geophys. Res., 99, 1042110442, 1994a. 
Jensen, E. J., Toon, O. B., Westphal, D. L., Kinne, S., and Heymsfield, A. J.: Microphysical modeling of cirrus 2. Sensitivity studies, J. Geophys. Res., 99, 10443-10454, doi:10.1029/94JD00226, 1994b.

Jensen, E. J., Lawson, R. P., Bergman, J. W., Pfister, L., Bui, T. P., and Schmitt, C. G.: Physical processes controlling ice concentrations in synoptically forced, midlatitude cirrus, J. Geophys. Res.-Atmos., 118, 5348-5360, doi:10.1002/jgrd.50421, 2013.

Kärcher, B.: Simulating gas-aerosol-cirrus interactions: Processoriented microphysical model and applications, Atmos. Chem. Phys., 3, 1645-1664, doi:10.5194/acp-3-1645-2003, 2003.

Kärcher, B. and Lohmann, U.: A parameterization of cirrus cloud formation: Heterogeneous freezing, J. Geophys. Res., 108, 4402, doi:10.1029/2002JD003220, 2003.

Kärcher, B. and Ström, J.: The roles of dynamical variability and aerosols in cirrus cloud formation, Atmos. Chem. Phys., 3, 823838, doi:10.5194/acp-3-823-2003, 2003.

Klett, J.: Stable analytical inversion solution for processing Lidar returns, Appl. Opt., 20, 211-220, 1981.

Kienast-Sjögren, E., Rolf, C., Seifert, P., Krieger, U. K., Luo, B. P., Wienhold, F. G., Krämer, M., and Peter, T.: Radiative properties of mid-latitude cirrus clouds derived by automatic evaluation of lidar measurements, Atmos. Chem. Phys. Discuss., in preparation, 2015.

Koop, T.: Homogeneous ice nucleation in water and aqueous solutions, Z. Phys. Chem., 218, 1231-1258, 2004.

Koop, T., Luo, B., Tsias, A., and Peter, T.: Water activity as the determinant for homogeneous ice nucleation in aqueous solutions, Nature, 406, 611-614, doi:10.1038/35020537, 2000.

Kovalev, V. and Eichinger, W.: Elastic Lidar, Wiley Online Library, 2004.

Kuettner, J. P. and O'Neill, T. H. R.: ALPEX - The GARP mountain subprogram, B. Am. Meteorol. Soc., 67, 793-805, 1981.

Kunz, A., Spelten, N., Konopka, P., Müller, R., Forbes, R. M., and Wernli, H.: Comparison of Fast In situ Stratospheric Hygrometer (FISH) measurements of water vapor in the upper troposphere and lower stratosphere (UTLS) with ECMWF (re)analysis data, Atmos. Chem. Phys., 14, 10803-10822, doi:10.5194/acp14-10803-2014, 2014.

Lin, H., Noone, K. J., Ström, J., and Heymsfield, A. J.: Small ice crystals in cirrus clouds: A model study and comparison with in situ observations, J. Atmos. Sci., 55, 1928-1939, doi:10.1175/1520-0469(1998)055<1928: SICICC>2.0.CO;2, 1998a.

Lin, H., Noone, K. J., Ström, J., and Heymsfield, A. J.: Dynamical influences on cirrus cloud formation process, J. Atmos. Sci., 55, 1940-1949, doi:10.1175/15200469(1998)055<1940:DIOCCF>2.0.CO;2, 1998 b.

Lott, F. and Miller, M. J.: A new subgrid-scale orographic drag parameterization: Its formulation and testing, Q. J. Roy. Meteorol. Soc., 123, 101-127, 1997.

Luo, B. P., Peter, T., Fueglistaler, S., Wernli, H., Wirth, M., Kiemle, C., Flentje, H., Yushkov, V. A., Khattatov, V., Rudakov, V., Thomas, A., Borrmann, S., Toci, S. G, Mazzinghi, P., Beuermann, J., Schiller, C., Cairo, F., Di Donfrancesco, G., Adriani, A., Volk, C. M., Strom, J., Noone, K., Mitev, V., MacKezie, R. A., Carslaw, K. S., Trautmann, T., Santacesaria, V., and Stefanutti, L.: Dehydration potential of ultrathin clouds at the tropical tropopause, Geophys. Res. Lett., 30, 1557, doi:10.1029/2002GL016737, 2003a.

Luo, B. P., Voigt, C., Fueglistaler, S., and Peter, T.: Extreme NAT supersaturations in mountain wave ice PSCs: A clue to NAT formation, J. Geophys. Res., 108, 4441, doi:10.1029/2002JD003104, 2003b.

Marcolli, C., Gedamke, S., Peter, T., and Zobrist, B.: Efficiency of immersion mode ice nucleation on surrogates of mineral dust, Atmos. Chem. Phys., 7, 5081-5091, doi:10.5194/acp-7-50812007, 2007.

Miltenberger, A. K., Pfahl, S., and Wernli, H.: An online trajectory module (version 1.0) for the nonhydrostatic numerical weather prediction model COSMO, Geosci. Model Dev., 6, 1989-2004, doi:10.5194/gmd-6-1989-2013, 2013.

Mishchenko, M. I., Travis, L. D., and Mackowski, D.W.: T-matrix computations of light scattering by nonspherical particles: A review (Reprinted from vol 55, 535-575, 1996), J. Quant. Spectrosc. Ra., 111, 1704-1744, doi:10.1016/0022-4073(96)00002-7, 2010.

Muhlbauer, A., Ackerman, T. P., Comstock, J. M., Diskin, G. S., Evans, S. M., Lawson, R. P., and Marchand, R. T.: Impact of large-scale dynamics on the microphysical properties of midlatitude cirrus, J. Geophys. Res.-Atmos., 119, 3976-1996, doi:10.1002/2013JD020035, 2014a.

Muhlbauer, A., Berry, E., Comstock, J. M., and Mace, G. G.: Perturbed physics ensemble simulations of cirrus on the cloud system-resolving scale, J. Geophys. Res.-Atmos., 119, 47094735, doi:10.1002/2013JD020709, 2014b.

Murphy, D. M.: Rare temperature histories and cirrus ice number density in a parcel and a one-dimensional model, Atmos. Chem. Phys., 14, 13013-13022, doi:10.5194/acp-14-13013-2014, 2014.

Myhre, G., Shindell, D., Breon, F.-M., Collins, W., Fuglestvedt, J., Huang, J., Koch, D., Lamarque, J.-F., Lee, D., Mendoza, B., Nakajima, T., Robock, A., Stephens, G., Takemura, T., and Zhang, H.: Climate change 2013: The physical science basis. Contribution of working group I to the fifth assessment report of the Intergovernmental Panel on Climate Change, edited by: Stocker, T. F., Qin, D., Plattner, G.-K., Tignor, M., Allen, S. K., Boschung, J., Nauels, A., Xia, Y., Bex, V., and Midgley, P. M., Cambridge University Press Cambridge, United Kingdom and New York, NY, USA, 2013.

Nastrom, G. D. and Fritts, D. C.: Sources of mesoscale variability of gravity waves. Part I: Topographic excitation, J. Atmos. Sci., 49, 101-110, 1992.

Platt, C. M. R. and Harshvardhan: Temperature dependence of cirrus extinction: Implications for climate feedback, J. Geophys. Res., 93, 11051-11058, 1988.

Pruppacher, H. R. and Klett, J. D.: Microphysics of clouds and precipitation, Kluwer Academic Publishers New York, ISBN: 07923-4211-9, 1997.

Raymond, W. H.: High-order low-pass implicit tangent filters for use in finite area calculations, Mon. Weather Rev., 116, 21322141, 1988.

Reinhardt, T. and Seifert, A.: A three-category ice scheme for LMK, COSMO Newsletter, 6, 115-120, 2006.

Rolf, C., Krämer, M., Schiller, C., Hildebrandt, M., and Riese, M.: Lidar observation and model simulation of a volcanicash-induced cirrus cloud during the Eyjafjallajökull eruption, 
Atmos. Chem. Phys., 12, 10281-10294, doi:10.5194/acp-1210281-2012, 2012.

Rollins, A. W., Thornberry, T. D., Gao, R. S., Smith, J. B., Sayres, D. S., Sargent, M. R., Schiller, C., Krämer, M., Spelten, N., Hurst, D. F., Jordan, A. F., Hall, E. G., Vömel, H., Diskin, G. S., Podolske, J. R., Christensen, L. E., Rosenlof, K. H., Jensen, E. J., and Fahey, D. W.: Evaluation of UT/LS hygrometer accuracy by intercomparison during the NASA MACPEX mission, J. Geophys. Res., 119, 1915-1935, doi:10.1002/2013JD020817, 2014.

Sassen, K. and Comstock, J. M.: A midlatitude cirrus cloud climatology from the facility for atmospheric remote sensing. Part III: Radiative properties, J. Atmos. Sci., 58, 2113-2127, 2001.

Schmidt, C. T. and Garrett, T. J.: A simple framework for the dynamic response of cirrus clouds to local diabatic radiative heating, J. Atmos. Sci., 70, 1409-1422, doi:10.1175/JAS-D-12056.1, 2013.

Schotland, R. M., Sassen, K., and Stone, R.: Observations by Lidar of Linear Depolarization Ratios for Hydrometeors, J. Appl. Meteor., 10, 1011-1017, doi:10.1175/15200450(1971)010<1011:OBLOLD>2.0.CO;2, 1971.

Schraff, C. H.: Data assimilation and mesoscale weather prediction: A study with a forecast model in the Alpine Region. PhD dissertation No. 11627, Federal Institute of Technology, Zurich, 1996.

Schraff, C. H.: Mesoscale data assimilation and prediction of low stratus in the Alpine region, Meteor. Atmos. Phys., 64, 21-50, 1997.

Seifert, P., Ansmann, A., Müller, D., Wandinger, U., Althausen, D., Heymsfield, A. J., Massie, S. T., and Schmitt, C.: Cirrus optical properties observed with Lidar, radiosonde, and satellite over the tropical Indian Ocean during the aerosol-polluted northeast and clean maritime southwest monsoon, J. Geophys. Res.-Atmos., 112, 2156-2202, doi:10.1029/2006JD008352, 2007.

Sherwood, S. C., Bony, S., and Dufresne, J.-L.: Spread in model climate sensitivity traced to atmospheric convective mixing, Nature, 505, 37-42, doi:10.1038/nature12829, 2014.

Skamarock, W. C.: Evaluating mesoscale NWP models using kinetic energy spectra, Mon. Weather Rev., 132, 3019-3032, 2004.

Solomon, S., Qin, D., Manning, M., Chen, Z., Marquis, M., Averyt, K. B., Tignor, M., and Miller, H. L. (Eds.): IPCC 2007: Climate change 2007: The physical science basis. Contribution of working group I to the fourth assessment report of the Intergovernmental Panel on Climate Change, Cambridge University Press, 2007.
Spichtinger, P. and Krämer, M.: Tropical tropopause ice clouds: a dynamic approach to the mystery of low crystal numbers, Atmos. Chem. Phys., 13, 9801-9818, doi:10.5194/acp-13-98012013, 2013.

Stephens, G. L., Tsay, S.-C., Stackhouse Jr., P. W., and Flatau, P. $\mathrm{J}$.: The relevance of the microphysical and radiative properties of cirrus clouds to climate and climatic feedback, J. Atmos. Sci., 47, 1742-1753, 1990.

Stohl, A.: Computation, accuracy and applications of trajectories a review and bibliography, Atmos. Environ., 32, 947-966, 1998.

Stohl, A., Wotawa, G., Seibert, P., and Kromp-Kolb, H.: Interpolation errors in wind fields as a function of spatial and temporal resolution and their impact on different types of kinematic trajectories, J. Appl. Meteor., 34, 2149-2165, 1995.

Stohl, A., Haimberger, L., Scheele, M. P., and Wernli, H.: An intercomparison of results from three trajectory models, Meteorol. Appl., 8, 127-135, 2001.

Toon, O. B. and Miake-Lye, R. C.: Subsonic aircraft: Contrail and cloud effects special study (SUCCESS), Geophys. Res. Lett., 25, 1109-1112, 1998.

Wandinger, U.: Multiple-scattering influence on extinction- and backscatter-coefficient measurements with Raman and highspectral-resolution Lidars, Appl. Opt., 37, 417-427, 1998.

Wernli, H. and Davies, H. C.: A lagrangian-based analysis of extratropical cyclones. I: The method and some applications, Q. J. Roy. Meteor. Soc., 123, 467-489, doi:10.1002/qj.49712353811, 1997.

Wernli, H., Paulat, M., Hagen, M., and Frei, C.: SAL- A novel quality measure for the verification of quantitative precipitation forecasts, Mon. Weather Rev., 136, 4470-4487, 2008.

Wiacek, A., Peter, T., and Lohmann, U.: The potential influence of Asian and African mineral dust on ice, mixed-phase and liquid water clouds, Atmos. Chem. Phys., 10, 8649-8667, doi:10.5194/acp-10-8649-2010, 2010.

Zieger, P., Kienast-Sjögren, E., Starace, M., von Bismarck, J., Bukowiecki, N., Baltensperger, U., Wienhold, F. G., Peter, T., Ruhtz, T., Collaud Coen, M., Vuilleumier, L., Maier, O., Emili, E., Popp, C., and Weingartner, E.: Spatial variation of aerosol optical properties around the high-alpine site Jungfraujoch (3580 ma.s.1.), Atmos. Chem. Phys., 12, 72317249, doi:10.5194/acp-12-7231-2012, 2012. 